\title{
A TAXONOMY OF EXPERT ELEVATOR AND AMUSEMENT DEVICE INSPECTOR KNOWLEDGE
}

\author{
by \\ Andrew Novak \\ BASc, University of Toronto, 2007
}

A thesis presented to Ryerson University

in partial fulfillment of the requirements for the degree of

Master of Applied Science

in the Program of

Mechanical Engineering

Toronto, Ontario, Canada, 2009

(C) Copyright Andrew Novak 2009 


\section{Author's declaration}

I hereby declare that I am the sole author of this thesis.

I authorize Ryerson University to reproduce this thesis to other institutions or individuals for the purpose of scholarly research.

I further authorize Ryerson University to reproduce this thesis by photocopying or by other means, in total or in part, at the request of other institutions or individuals for the purpose of scholarly research. 


\title{
A TAXONOMY OF EXPERT ELEVATOR AND AMUSEMENT DEVICE INSPECTOR KNOWLEDGE
}

\author{
Andrew Novak \\ Master of Applied Science \\ Mechanical Engineering \\ Ryerson University \\ 2009
}

\section{Abstract}

This thesis presents a taxonomy of expert elevator and amusement device inspector knowledge that was developed using task and cognitive task analysis. While literature concerning research into quality control inspection exists, very little research has been performed into safety inspection. A qualitative study captured the knowledge used by elevator and amusement device inspection. The existence of expert performance in the elevator and amusement device inspection domains was identified and a taxonomy of expert inspector knowledge was created. This taxonomy was based on a model of knowledge that distinguishes between three types of knowledge--declarative, procedural, and strategic. Further development of this taxonomy, along with an effort to perform expert inspector knowledge capture, is expected to lead to improved inspector training and performance, and an increase in consistency between the inspections performed by all inspectors. 


\section{Acknowledgments}

I would like to thank the TSSA and the inspectors who participated in this research for the time and the other contributions that they made to this project.

I would also like to thank Dr. Woodcock for providing advice and guidance throughout this research. 


\section{Table of contents}

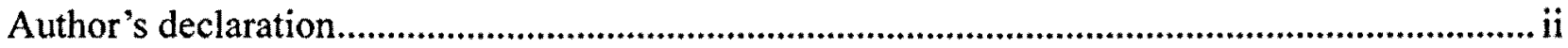

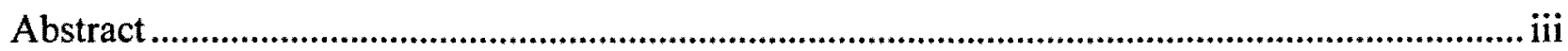

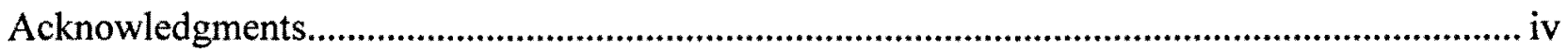

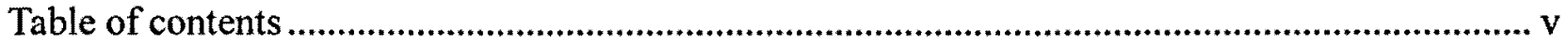

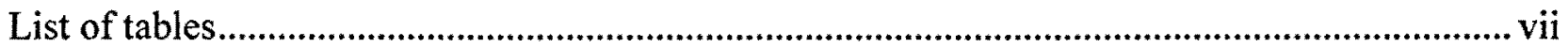

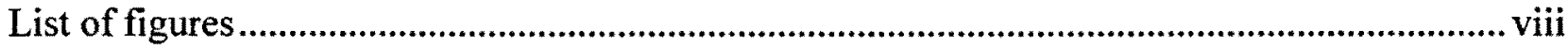

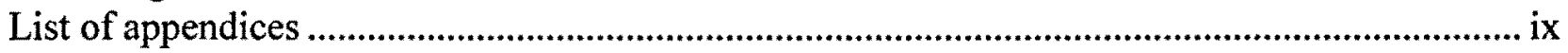

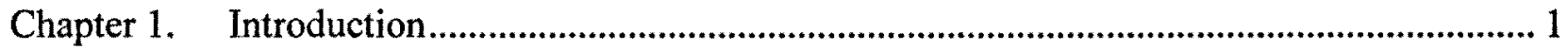

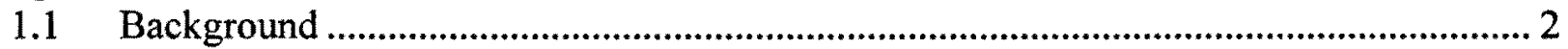

1.1.1 Task challenges in the performance of amusement ride inspection........................... 4

1.1.2 Modeling safety inspection: Case of amusement ride inspection ............................... 7

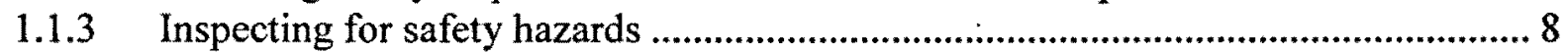

1.2 The Technical Standards and Safety Authority ............................................................... 8

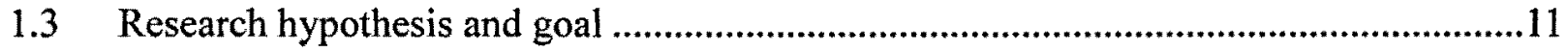

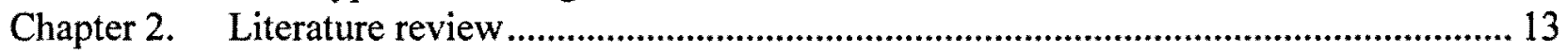

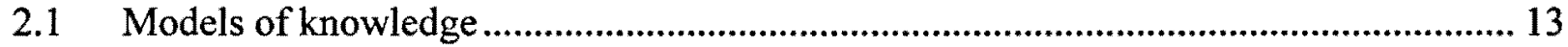

2.1.1 Explicit, implicit, and tacit knowledge ............................................................. 13

2.1.2 Strategic, procedural, and declarative knowledge ....................................................... 14

2.1.3 Comparison of the models of knowledge ................................................................. 15

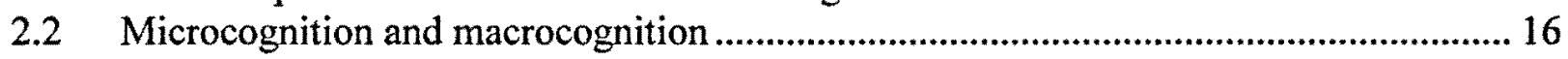

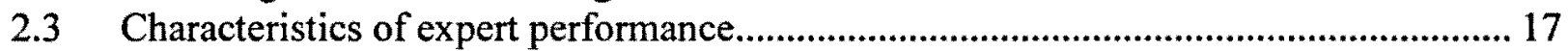

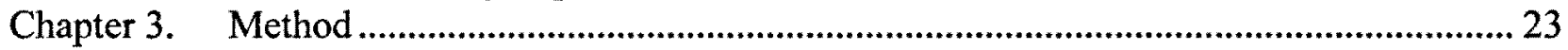

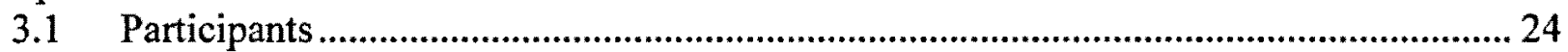

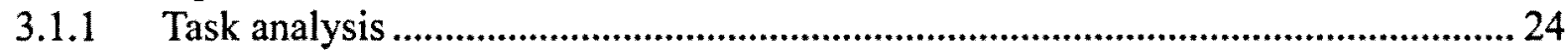

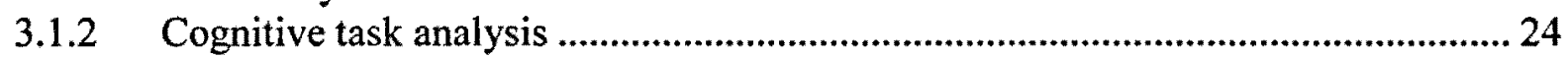

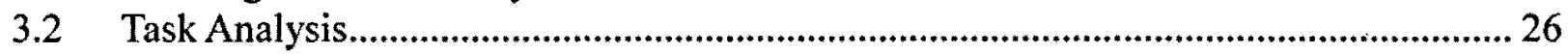

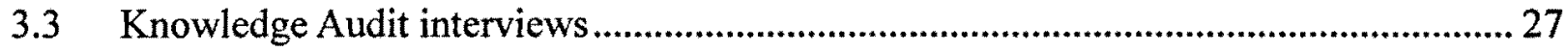

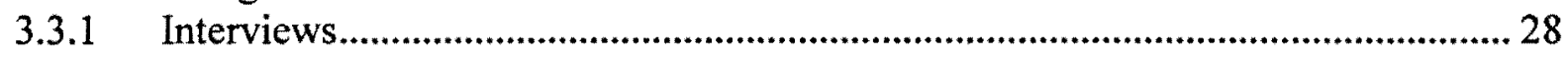

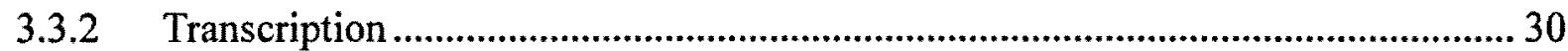

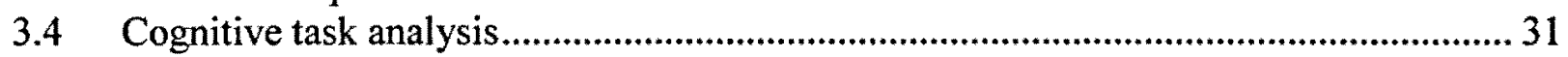

3.4.1 Identification of the characteristics of expert performance ....................................... 31

3.4.2 Creation of taxonomies of expert inspector knowledge …........................................ 31

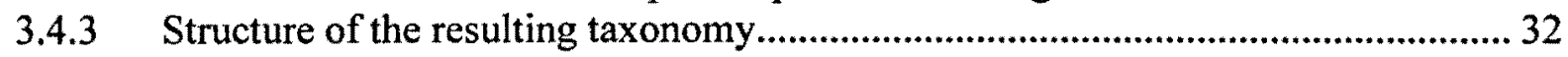

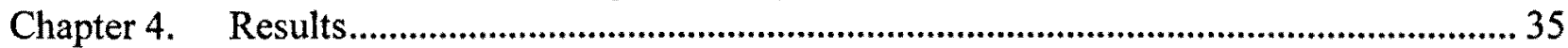

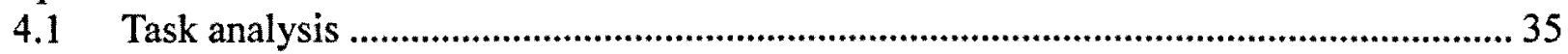

4.1.1 Task analysis of expert hydraulic elevator inspection ............................................ 35

4.1.2 Task analysis of expert amusement device inspection............................................. 36

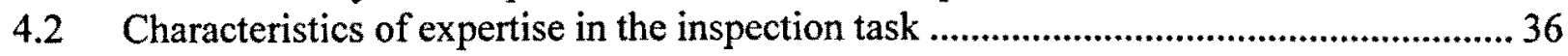

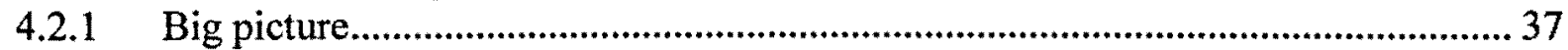

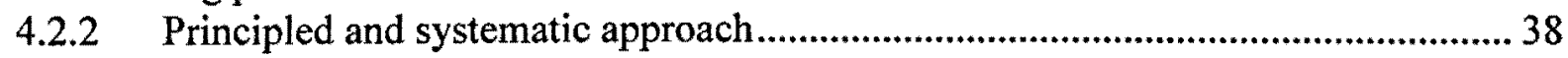

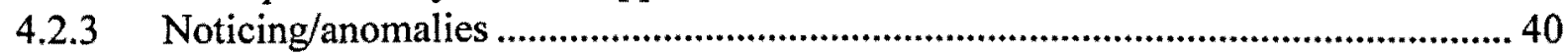

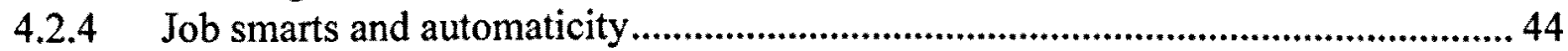

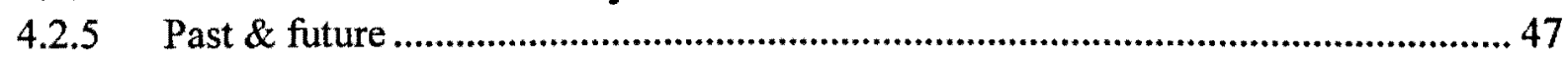

4.2.6 Opportunities/improvising and self-monitoring ................................................... 48 


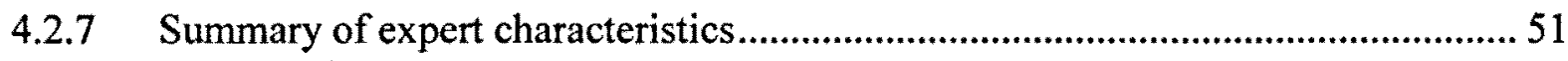

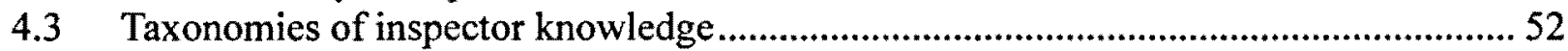

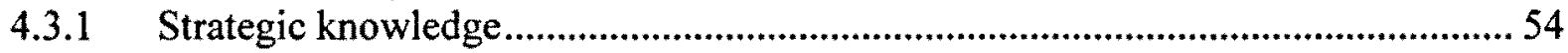

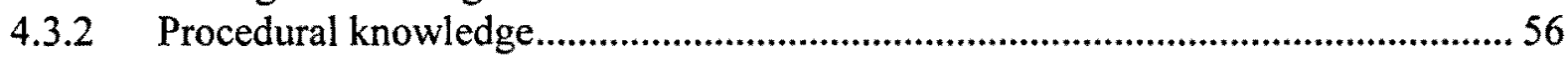

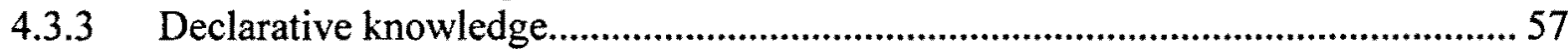

4.4 The difference between elevator device and amusement device inspection ............... 62

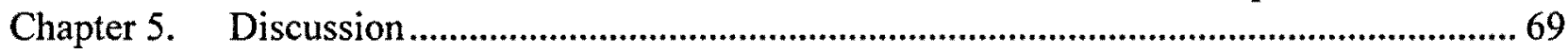

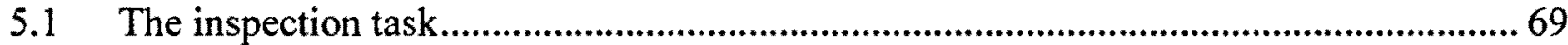

5.2 Strategic, procedural, and declarative knowledge......................................................... 70

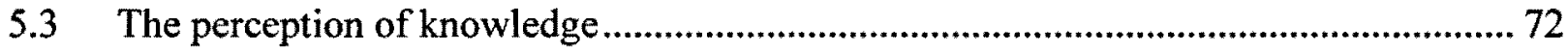

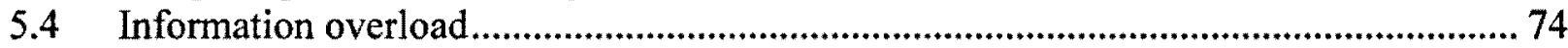

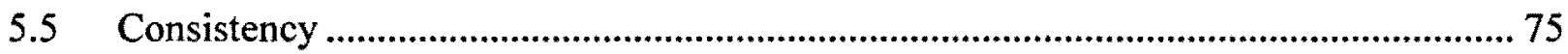

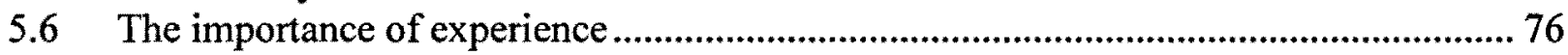

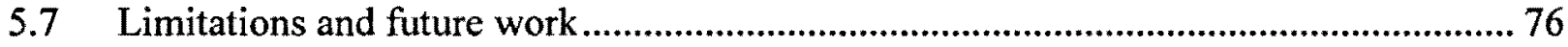

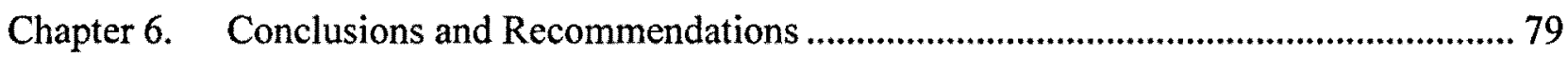

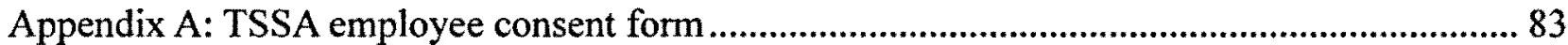

Appendix B: Task analysis of periodic hydraulic ED inspection .................................................... 85

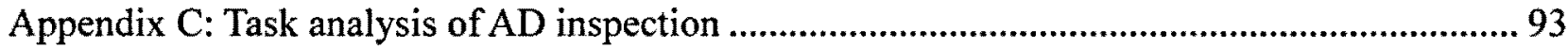

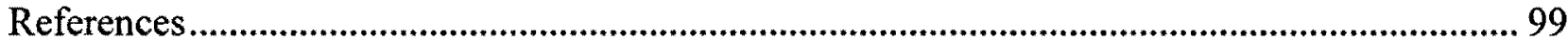




\section{List of tables}

Table 1. Knowledge Audit probes (Militello \& Hutton, 2008) .....................................................29

Table 2. Relationship between initial analysis themes and knowledge model .............................. 53

Table 3. Taxonomy of strategic knowledge ...................................................................................... 55

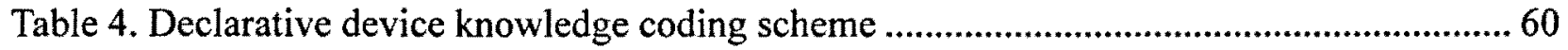

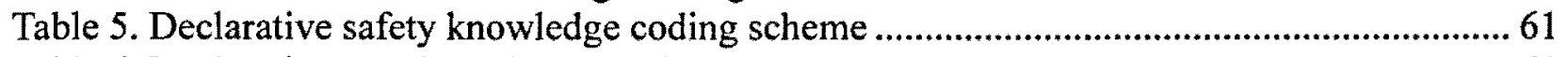

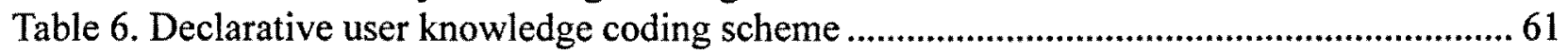

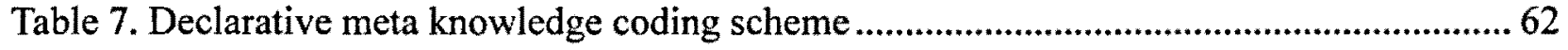




\section{List of figures}

Figure 1. Research outline 23

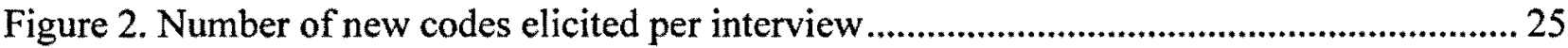

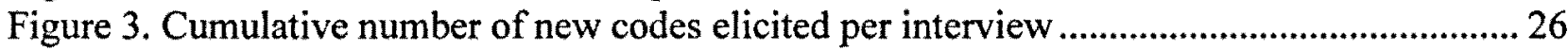

Figure 4. Top level of periodic hydraulic elevator inspection task ................................................35

Figure 5. Top level of amusement device inspection task .............................................................. 36 


\section{List of appendices}

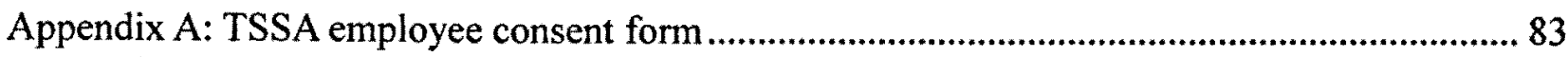

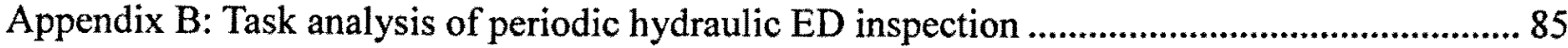

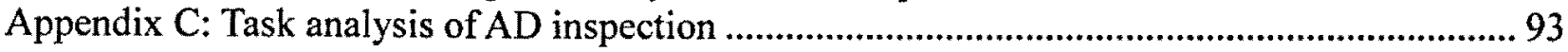




\section{Chapter 1. Introduction}

Inspection plays an important role in the management of safety in many systems. Unlike quality control, safety inspection involves not just the identification of a specific set of defects in a system, and unlike troubleshooting or accident investigation, safety inspection does not just involve the identification of causes for specific symptoms that a system is displaying. Safety inspectors are tasked with not just identifying or investigating particular cues or specific safety hazards in a system, they are tasked with evaluating the safety of entire systems, such as elevators, restaurant kitchens, or factories, which may often appear to be functioning normally. In many cases, such as with elevators and restaurants, where inspectors are providing licenses or permits based on their inspections, they are also largely taking responsibility for the safety of those entire systems, because if an accident were to occur in those systems, the performance of the inspector would be one of the first things brought into question. As such, safety inspectors are often the lynchpin that is expected to ensure that no accidents occur within the system that they are responsible for. Yet accidents do occur, and they occur in systems that have been inspected, and so, as part of their job description, many inspectors are required to provide licenses that declare the safety of systems that, in spite of those licenses, and in spite of the quality of inspection, may have accidents occur within them. Yet although it may be impossible to ever completely prevent accidents from occurring, high-quality inspections are likely to decrease the probability of the occurrence of those accidents.

When faced with inspecting a system in which a large number of accidents may occur, how do inspectors cope with managing all of the cues for all of those potential safety hazards? And what characterizes the performance of expert safety inspectors? This thesis examines these questions. 


\subsection{Background}

Research in the human factors literature concerning inspection largely addresses the performance of visual quality control inspection and the design of aids for that domain, particularly in the aircraft inspection domain. In Patel et al. (1994), the redesign of aircraft inspection workcards was described. In this paper, the aircraft inspection task was presented as a visual quality control process in which specific components of the aircraft must be inspected for specific defects. In this type of task, checklists and workcards were identified as being effective, because each quality control check, along with the nature of the deficiencies that the check entails inspecting for, could be documented. Gramopadhye et al. (1997), Latorella and Prabhu (2000), Melloy et al. (2002), and Taylor et al. (2004) also investigated the performance of inspectors, but only from the microcognitive perspective of their visual inspection performance (for a discussion of microcognition, refer to the Literature Review chapter of this thesis).

Other perspectives have been taken when studying the inspection of systems, such as in Subhash (2008), in which the identification of inspection intervals was studied, based on the hazard rate of a system versus the cost of inspection and the cost of repair. Laitinen et al. (1999) studied the relationship between safety inspections and the occurrence of accidents at construction sites, but similar to the aircraft inspections in the studies previously discussed, the safety inspection that was employed in this study was defined through a checklist containing a fixed number of defects to be inspected at each construction site. Auld et al. (2001) similarly investigated the relationship between construction site inspection and the occurrence of accidents, but the authors do not in any way define the inspection task that is performed at these sites.

Hamada et al. (2002) developed a ship inspection support system based on the PDCA (plan-docheck-action) model of quality control inspections. This system contained four subsystems: (1) a 
ship inspection simulator that identifies the probabilities of finding damage in the various parts of the ship, (2) a system to input the actual inspection data, (3) a system that allows for comparison between the actual inspection data and the simulation data, and (4) and an information management system to manage all of this data. One of the main reasons for developing this system was that "current ship inspections rely on the experience of the workers. Therefore, it is difficult to understand, and hence to improve, the state of ship inspections" (p. 205). The authors' intention was to have all ship inspectors use the developed system, and as a result, follow the PDCA model of quality control. Kraus (1998) presented another inspector support system, although his system focused on simply computerizing resources that inspectors use in the field.

In Allocco (1997), the development of a general six-step model of inspector performance was discussed. The six steps of this model were as follows: (1) acquire system knowledge, (2) develop exposure criteria, (3) hypothesize and construct accident scenarios, (4) develop a design matrix, (5) acquire input for the matrix, and (6) conduct risk assessment. This model addressed safety inspection, but did so from a general perspective, and is intended for the inspection of unconventional areas, of which the inspector has limited knowledge.

In this literature review of safety inspector performance, no research that investigated the specific knowledge and skills of expert safety inspectors was found, and so many questions about the performance of safety inspectors remain unanswered: How do safety inspectors cope with performing inspections in which the number of possible deficiencies are too numerous to be stored in their memory? What characterizes the performance of expert safety inspectors?

In order to address this gap in the human factors research literature, Woodcock $(2003 ; 2007$; 2009) performed a series of three studies that investigated the task challenges involved in the 
amusement device inspection domain and created a model of amusement device inspection. These three studies are described below.

\subsubsection{Task challenges in the performance of amusement ride inspection}

In Woodcock (2003), the TOMES outline-task, operator, machine/materials/tools, environment, and society - was used to describe the amusement device inspection domain. Of most relevance to this thesis is her discussion of the inspection task, including the task approach that inspectors take, the sensory demands of the task, and the knowledge and decision-making that inspectors perform.

\section{Task approach}

In discussing the task approach to amusement device inspection, Woodcock described several strategies and heuristics employed by inspectors. These were as follows:

Consulting the documentation was a strategy that most inspectors performed, and was used to orient themselves with the device they are about to inspect, as well as provide them with suggestions for additional inspection points.

Mental models were identified as an important aspect of amusement device inspection.

Inspectors use and create mental models of devices in order to guide their inspection and to help them identify the aspects of a device that should be inspected.

Spatial, rather than functional, task breakdown of the device was employed in navigating through the device space during inspection.

Pattern recognition was used frequently by inspectors to identify potential defects or missing 
parts.

Heuristics ranging from mechanical signs and symptoms to organizational symptoms were used by inspectors as indications of potential defects, such as the 'feel' of ride doors, or the observation of grease or fresh paint.

Tools were used by inspectors to aid in their inspection, such as notepads as memory aids, binoculars to aid in inspected inaccessible points, measuring tapes and pen knives were also used, although most inspectors favored 'traveling light' rather than carrying a large number of tools.

Different cognitive styles were also observed among inspectors, with some inspectors emphasizing "direct visual and tactile contact with the ride to seek out the signs and symptoms or deficiencies, while other inspectors emphasized more intuitive approaches based on interaction with the owner and operator" (p.982).

\section{Sensory demands}

Following a discussion of these inspector strategies, Woodcock discusses the physical nature of the task, followed by a discussion of the sensory demands of the inspection task:

Visual inspection was used throughout the inspection, although a number of challenges existed for visual inspection, namely illumination or contrast, line of sight or distance, and visual noise, due to moving, detailed, and multicoloured elements in the environment. Individual differences between inspectors were also identified as potentially affecting performance of visual inspection.

Tactile inspection was also observed by Woodcock as being important, although tactile inspection faced a number of challenges, including interference due to protective equipment, such as gloves and boots, environmental temperatures, and individual differences, such as 
"strength, dexterity, or cuts and scratches" (p.983).

Auditory inspection was also performed by inspectors, where attention is paid to the sounds a device makes for any signs of potential defects. It is noted that the knowledge of sound indications are difficult to provide training for, as they cannot be provided through training notes. Inspectors also communicate with operators and mechanics and try to identify any potential defects from these conversations.

Smell may provide inspectors an indication that there is a defect with a device, such as with the smell of overheated oil. Smell indications, as with auditory ones, are difficult to provide training for.

\section{Knowledge and decision-making}

Deciding what to inspect during an inspection is identified by Woodcock as a "logical exercise that takes into account the state of the ride at the previous inspection, then considers the possible and probable changes from that state, taking into account generic knowledge (mechanical, structural, and material properties) and system knowledge (what has been assembled, transported, maintained, and by whom, since the last inspection)" (p. 983). Inspectors are also influenced by the "regulatory requirements and conventions, norms, and reference materials" (p. 983). In addition to these factors, knowledge of past accidents with the specific or similar devices was identified as being an important reference for inspectors when identifying what to inspect.

A discussion of amusement device inspection checklists is also provided, in which checklists are identified as providing an inspection framework to the inspectors, but not as providing all of the information that is required by an inspector. 


\subsubsection{Modeling safety inspection: Case of amusement ride}

\section{inspection}

In Woodcock (2007), a model of amusement device inspection was created through an immersive grounded-theory approach in which, over a period of four-and-a-half years, the researcher became an amusement device inspection trainee. This model describes the inspection of amusement devices as being performed from a holistic perspective, rather than a procedural perspective. This "holistic impression takes into account broad visual, auditory, and kinaesthetic patterns that the inspector associates with safety deficiencies [...] or certain structural or mechanical features that the inspector recognizes as prone to wear or failure or as being linked to a service bulletin or accident." According to this model, if nothing is identified during this holistic assessment, the inspectors then identify whether any specific device components require assessment, according to checklists and ride manuals.

If a concern was identified during the holistic assessment, the inspector confirms his certainty about the nature of the defect. If he is certain, he then identifies whether the deficiency is tolerable. If he is not certain, he attempts to resolve that uncertainty by looking for permissive authorities for the deficiency. If a permissive authority is found, the inspector may still identify the deficiency as a hazard. Otherwise, the inspector will accept the deficiency, but may suggest that it be monitored in the future.

Other strategies discussed by Woodcock in the description of this model include the review of ride documentation prior to the inspection, communication and cooperation between the inspector and those involved with the upkeep of the amusement device, the use of distributed cognition between inspectors, the use of comparison between similar device components, and the 
use and creation of mental models of potential outcomes of identified deficiencies. Distributed cognition was noted as being particularly important in the inspection of amusement devices as an aid to overcome the "knowledge, memory, and decision challenges in the inspection task," as "memorizing all of the inspection points of all rides is infeasible."

\subsubsection{Inspecting for safety hazards}

In Woodcock (2009), a survey was conducted among 105 safety inspectors, including food safety, workplace, and amusement device inspectors. The survey was intended to confirm observations developed in the previous two studies. This survey confirmed the wider variety of defect types that safety inspectors are responsible for when compared to quality inspection, and the importance of "decisions more nuanced than accept/reject" (p. 361). It also confirmed the importance of a multisensory approach to inspection, the use of distributed cognition by all types of inspectors, the lack of performance feedback, and a difference in performance between experts and novices in performing risk-based decision making.

Woodcock concludes that "the signal-detection theory model used for quality inspection studies is infeasible with the ill-defined open-loop task" (p. 361), and that "while the diversity of inspection environments limits the opportunity to thoroughly predefine the task for training and checklists, safety inspectors would likely benefit from supports to reduce uncertainty" (p. 361).

\subsection{The Technical Standards and Safety Authority}

The previous research in the amusement device inspection domain will be extended in this thesis. This thesis will examine the knowledge and skills used by safety inspectors in more detail than was done in these previous studies, and will expand to include elevating device as well as amusement device inspection, as this enables the study of the same inspector population in two 
distinct contexts. In Ontario, both amusement devices and elevating devices are regulated by the Technical Standards and Safety Authority (TSSA). Approximately 43,000 elevating devices and 1,600 amusement devices are licensed under the authority of the TSSA. Among the TSSA's responsibilities are reviewing and registering elevating device designs, conducting initial inspections, licensing devices, and conducting periodic inspections of these devices (Technical Standards and Safety Authority [TSSA], n.d). Whether or not a device is licensed depends on whether they conform to the Technical Standards \& Safety Act 2000, elevating device regulation, and adopted safety codes and standards (TSSA, n.d).

There are currently 65 amusement and elevator device inspectors employed by the TSSA, and generally one or two new inspectors are hired each year, although recently, a large influx of new inspectors were hired to help meet the increasing demand for inspectors throughout Ontario. When a new inspector joins the TSSA, it is generally accepted that it will take between five to ten years of work experience to gain a level of proficiency at which they can be considered experts (Woodcock, 2007).

Although the TSSA is only responsible for regulated devices in Ontario, the TSSA benchmarks its performance to national and international organizations of regulatory inspection, such as the National Association of Amusement Ride Safety Officials (NAARSO), which is situated in the US. Because of this, situating the study within the TSSA's elevator and amusement device inspector group should provide insights relevant beyond Ontario and the TSSA alone.

\section{Inspector training at the TSSA}

Training for elevator device inspection at the TSSA is currently provided in two settings, the classroom and in the field through job shadowing. In the classroom, trainers primarily provide 
factual information concerning device codes, policies, health and safety, and specific device knowledge that an inspector is required to know to perform their work. Job shadowing, on the other hand, is meant to provide the inspector with the inspection skills that are required of them to expertly judge whether or not a device is safe.

Whereas the goal of the classroom portion of inspector training is to impart a single type of knowledge to inspectors-explicit knowledge, i.e. factual information about the inspection task-the goal of on-the-job training is to impart three types of knowledge, explicit knowledge, implicit knowledge, and tacit knowledge (for a discussion of this model of knowledge, refer to the Literature Review chapter). In on-the-job training, the inspectors are meant to be learning the 'what' and the 'how' of inspection—what are the tasks that expert inspectors perform in the course of an inspection and how do expert inspectors perform those tasks. A discussion of these three types of knowledge-explicit, implicit, and tacit—was provided in the Literature Review chapter of this paper.

There is a marked difference in design between the classroom and the on-the-job training portions of inspector training. Whereas the classroom training is formalized, with a specific syllabus, required hours for each topic, and prepared presentations, the on-the-job training is not. Any knowledge that an inspector receives from each on-the-job training session resides inside, and is completely dependent on, the inspector providing that training and the specific devices and situations the trainer and trainee encounter together. As such, there are two problems that currently exist with the on-the-job portion of elevator inspector training:

1. The on-the-job training is in no way documented or formalized, and there is no syllabus or specific structure to this training program

2. The on-the-job training was not formally designed to impart implicit or tacit knowledge 
to inspectors undergoing the training, and as was previously discussed, if implicit and tacit knowledge are not formally addressed in the design of training, it is unlikely that they will be communicated through training.

Amusement device inspection training at the TSSA takes a different form than the elevator device inspection training. Amusement device inspectors at the TSSA must have NAARSO (National Association of Amusement Ride Safety Officials) certification, which is a multi-level certification process which requires 1000 hours of job shadowing, and the passing of written tests at each level (National Association of Amusement Ride Safety Officials [NAARSO], 2009). There are a number of important differences between elevator inspection training and amusement device inspection. One of these is frequency of work. While an inspector performs elevator inspections almost daily, that same inspector may only spend 70 hours over an entire year performing amusement ride inspections. Another is that amusement rides are much more varied in terms of design, and so inspectors are less able to follow a fixed procedure than they are when performing elevator inspection. In spite of this, the structure of amusement device training follows roughly the same formula, being a combination of seminars and on-the-job experience, and so it faces many of the same issues as elevator device inspection training.

\subsection{Research hypothesis and goal}

In the discussion of the background for this thesis, a gap in the human factors research literature concerning the performance of safety inspection was identified. Three papers attempting to fill that gap by exploring the amusement device inspection task (Woodcock, 2003; 2007) and the safety inspection task in general (Woodcock, 2009) were discussed. Although these papers explore the device inspection task and discuss a number of strategies used by inspectors, they do 
not describe the full composition and structure of the knowledge used by inspectors.

The hypothesis of this thesis is that the disparate knowledge and strategies referred to in Woodcock $(2003 ; 2007 ; 2009)$ can be collected and organized into a cohesive taxonomy of expert safety inspector knowledge through a task and cognitive task analysis of the inspection task. The goal of this thesis is to produce a taxonomy of expert elevator and amusement device knowledge upon which further performance-support development could be based. 


\section{Chapter 2. Literature review}

In order to address the questions raised in the first chapter of this thesis from a human factors perspective, research was done into the nature of human cognition and knowledge, as well as into the nature of expert performance. The reviews of these two subjects are provided in the following sections.

\subsection{Models of knowledge}

\subsubsection{Explicit, implicit, and tacit knowledge}

One of the ways of looking at knowledge is by separating it into explicit and tacit knowledge (Cooke, 1994). Explicit knowledge concerns facts, rules, and procedures that are consciously accessible and known. Tacit knowledge, on the other hand, is unconscious and automatic and is therefore often unspoken. Between these two poles of the spectrum of knowledge, a third type of knowledge has recently been suggested, implicit knowledge (Frappaolo, 2008; Meyer and Sugiyama, 2007). Whereas tacit knowledge is knowledge that is unconscious and automatic, and explicit knowledge is the type of factual knowledge that can be found in textbooks, implicit knowledge is knowledge that can be captured and presented, but that has not yet been because the existence and the structure of that knowledge is not immediately recognizable.

When a system requires individuals to only be aware of specific facts or procedures (i.e., explicit knowledge), traditional training methods will likely suffice, but when a system requires good mental models of the functioning of that system or requires specific perceptual skills (i.e., implicit or tacit knowledge), traditional training methods can be inadequate.

An example of this is on-the-job training. Most of an expert's expertise does not take the form of 
explicit knowledge (Clark \& Estes, 1996), and so many experts are not fully conscious of much of the knowledge that they use while performing their work. In on-the-job training, therefore, the expert often cannot articulate much of his knowledge, and as a result, this knowledge will not be transferred to the novice. In fact, it may not even be the case that experts are the most effective individuals at training novices. Hinds et al. (2001) found that novices who were trained for a task by novices actually performed better on this task than those who were trained by experts. The researchers believed that this was due to the fact that the experts had more abstract mental models than did the novices, and so there was a disconnect between the mental models of novices and experts. This was not the case when both the instructor and the student were novices, as they had more compatible mental models. On the other hand, the researchers also found that novices instructed by experts performed better on a task that was related to, but not the same as, the one for which they were trained. This indicated that those instructed by experts likely had a stronger general mental model of the system, and so the long-term effects of training received by experts may still be preferable. Yet without a detailed understanding of the knowledge involved in safety inspection tasks, such as is performed in expert elevator and amusement device inspection, the effectiveness of both classroom training and on-the-job training at transforming a novice inspector into an expert inspector will likely be sub-optimal.

\subsubsection{Strategic, procedural, and declarative knowledge}

Gott (1988) discussed a three-part model of practical performance that consists of: (1) strategic knowledge (or 'how-to-decide-what-to-do-and-when') knowledge, (2) procedural (or knowledge 'about how to do' things) knowledge, and (3) declarative (or knowledge 'about' things) knowledge. Declarative knowledge refers to factual knowledge 'about' things, such as knowledge about the elevator and amusement devices, knowledge about the users of those devices, and 
knowledge about the inspector himself, such as how they work and how they learn. Procedural knowledge "refers to knowledge about doing things", "and much of this knowledge is represented as heuristics and strategies" (Schraw, 1998, p. 114). Strategic knowledge refers to knowledge about knowing what to do and when to do it, and acts as a control function that accesses declarative and procedural knowledge at the appropriate times. This model was reiterated in Schaafstal (1993) as a framework for troubleshooting, was discussed in-depth in McCormick (1997), and is essentially the conceptual framework for the CommonKADS methodology (Schreiber et al., 2000). Clark and Estes (1996) described the difference between declarative and procedural knowledge, as follows: "whereas the purpose of declarative knowledge is to handle novelty, the purpose of procedural knowledge is to automate mental strategies and skills that are more routine" (p. 407). Strategic knowledge provides a controlling structure to the entire task by providing the high-level goals of the task. These goals are then achieved through the use of procedural and declarative knowledge.

\subsubsection{Comparison of the models of knowledge}

The goal of this thesis is to capture not just the explicit knowledge involved in the inspection task, but also the implicit and, if possible, the tacit knowledge of the inspection task. An important differentiation between this model and the strategic/procedural/declarative model of knowledge is that the explicit/implicit/tacit model characterizes knowledge in terms of its own nature, namely, its accessibility to those who have and make use of it, but it does not characterize knowledge in terms how that knowledge is applied in the real world, which the strategic/procedural/declarative model does.

As a result, a taxonomy of inspector knowledge that is built around the strategic/procedural/ 
declarative model of knowledge would be more closely representative of how inspectors use their knowledge while performing the inspection task. In the creation of the expert inspector knowledge taxonomies, it is expected that inspector knowledge will be made up of the three types of knowledge represented in this knowledge model.

\subsection{Microcognition and macrocognition}

Microcognition is concerned with the "building blocks of cognition, the processes that we believe are invariant and serve as the basis for all kinds of thinking and perceiving" (Klein et al. $2003, p .81$ ) (such as memory and attention) and it arose with the increasing importance of cognitive tasks over physical tasks in the workplace. Microcognition is based on reductionism, i.e., that it is possible to explain human actions by decomposing them into their basic cognitive 'building blocks' (Klein et al., 2003).

Whereas microcognition looks at the relationship between an individual and his work in isolation, much in the same way that physical ergonomics traditionally looks only at the direct relationship between an individual and his work, macrocognition looks at the relationships between individuals and their work with a much larger lens that incorporates the social and technological artifacts that also play a role in the system (Hollnagel, 2001). The difference between micro and macrocognition can be thought of as the difference between 'cognition in captivity' and 'cognition in the wild' (Hollnagel, 2001). According to Klein et al, (2003), some of the main functions that fall under macrocognition are: naturalistic decision making, sensemaking, planning, adaptation, problem detection, and coordination; and some of the main processes include: maintaining common ground, developing mental models, mental simulation and story boarding, managing uncertainty and risk, identifying leverage points, and managing 
attention. One of the primary techniques that has arose in order to better capture and understand macrocognition is cognitive task analysis (CTA).

When looking at the findings of past studies of amusement ride inspection (Woodcock, 2003, 2007,2009 ), it would appear that the amusement device inspection task has many macrocognitive characteristics. Inspectors must often make discretionary diagnoses concerning the perceived danger of defects, and these judgments may be influenced by any number of factors and situational characteristics, as well as by the inspectors' understanding of each of the many different rides that must be inspected. Because of the close relationship between elevator inspection and amusement ride inspection—in Ontario, elevator and amusement device are regulated by the same organization and the inspectors of these devices are pulled from the same pool of professionals-it is likely that elevator inspection exhibits a similar macrocognitive nature.

\subsection{Characteristics of expert performance}

One of the primary purposes for which CTA is performed is in the development of training programs. The goal of any training program is to decrease the amount of time it takes for a novice to become an expert. Much research has been performed on the differences between experts and novices in a variety of domains. Discussions on some of the main characteristics of expert performance can be found in Farrington-Darby \& Wilson (2006), Feltovich et al. (2006), and in Crandall et al., (2006).

The structure of the following literature review on expert performance is based on the subjects of the probe questions that form the Knowledge Audit interview of the Applied Cognitive Task Analysis (ACTA), which is a specific cognitive task analysis technique. The Knowledge Audit is 
an interview technique that is driven by characteristics of expert performance that have been found to exist among experts across a variety of domains. This literature review was structured to discuss each of the primary characteristics of expert performance identified in the Knowledge Audit because these characteristics represent a majority of the concepts that were encountered in the expert performance literature. These characteristics are as follows: past \& future, big picture, noticing, job smarts, opportunities, self-monitoring, and anomalies.

In addition to these characteristics that make up the cognitive task analysis portion of this research project, two additional characteristics of expert performance that were identified in the literature are discussed: principled and systematic approach, and automaticity. The following section will summarize each of these briefly.

Past \& future and big picture. Militello and Hutton (1998) characterized 'past \& future' as "experts can figure out how a situation developed, and they can think into the future to see where the situation is going" (p. 1622), and they defined 'big picture' as "novices may only see bits and pieces [whereas] experts are able to quickly build an understanding of the whole situation" (p. 1622). Both of these characteristics of expert performance are supported in the literature. Experts have been found to represent their knowledge of a system at multiple levels of abstraction, where novices have been found to understand systems from a more superficial level (Frederiksen \& White, 1993, Chi, Glaser \& Farr, 1988). In addition, experts have been found to be more skilled than novices at anticipating and making predictions concerning systems (Cellier et al., 1997). In their review of expertise literature, Farrington-Darby and Wilson (2006) referenced a study of strategic decision making in bank managers that found that experts made more use of analogical reasoning and were less likely to make guesses concerning cause and effect relationships. These two differences between experts and novices are also related to differences in mental models 
between experts and novices, where experts have been found to have a deeper and more abstract mental model of the systems for which they are experts (Gitomer, 1988, Chi, Glaser \& Rees, 1982, Feltovich, Prietula, \& Ericsson, 2006). Experts' deeper and more abstract mental models of systems are in all likelihood what provides them with the abilities to both predict the 'past $\&$ future' and see the 'big picture' of the systems for which they are experts.

Noticing. 'Noticing' was characterized by Militello and Hutton (1998) as "experts are able to detect cues and see meaningful patterns that less-experienced personnel may miss altogether" (p. 1622). Chi, Glaser, and Farr (1988) stated the organization of an expert's knowledge base allows them to perceive large meaningful patterns in their domain that novices will not perceive. It has also been found that experts have highly developed perceptual and attention abilities, and are able to extract information from a system that others cannot (Phelps, 1977; Lesgold et al., 1988).

Job smarts. Characterized as "experts learn how to combine procedures and work the task in the most efficient way possible" by Militello and Hutton (1998, p. 1622), 'job smarts' is a recurring expert characteristic in the literature. Pokorny et al. (1996) found that troubleshooters who were trained using a CTA-developed program were more efficient in their troubleshooting, effectively identifying components that needed to be investigated and those that did not. The same study also found that those who were not given the CTA training were more likely to fail to investigate components that would have made their troubleshooting more efficient. Shanteau (1992) has similarly found that experts were able to identify which information was irrelevant when making classification decisions. Feltovich et al. (2006) identified selectivity, the "separation of signal from noise either in features extracted from events or on internal cognitive processes themselves" (p. 55), as an important expert characteristic.

Means and Gott (1988) also found that expert troubleshooters make use of rules concerning 
system performance that allow them to select appropriate strategies and eliminate inappropriate strategies, as well as to predict the outcome of those strategies. Hoffman and Lintern (2006) referenced the ethnographic research of Lave (1988) and Hutchins (1995) that showed that rather than simply following work rules and procedures, experts instead develop and make use of informal heuristic strategies that are both effective and efficient.

Opportunities/Improvising and anomalies. Militello and Hutton (1998) characterized this characteristic as "experts are comfortable improvising - seeing what will work in this particular situation; they are able to shift directions to take advantage of opportunities" (p. 1622). Experts are able to handle adversity better, and are able to adapt their decisions based on continuously developing information (Shanteau, 1988; Hogarth 1981). Chi (2006) also stated that experts "make use of whatever sources of information are available while solving problems". In addition to being better at adapting to situations, experts are also more aware of situations that are not typical. Militello and Hutton defined 'anomalies' as: "Novices don't know what is typical, so they have a hard time identifying what is atypical. Experts can quickly spot unusual events and detect deviations. And they are able to notice when something that ought to happen doesn't" (p. 1622).

Equipment difficulties. Militello and Hutton (1998) stated that "novices usually believe whatever the equipment tells them; they don't know when to be skeptical" (p. 1622).

Self-monitoring. Van Gog et al. (2005) found that experts spend more time evaluating their actions than do novices. Chi (2006) also stated that experts are more accurate at monitoring and evaluating both their performance of a task and their comprehension of a problem. Feltovich et al. (2006) stressed the importance of metacognition-a person's ability to reflect on their own thought processes-to expert performance, stating that "metacognition [...] is important for 
people to start testing their own understanding and partial solutions to a problem [which] prevents blind-alleys, errors, and the need for extensive back-up and retraction" (p. 56).

Principled and systematic approach. It has been found that expert troubleshooters employ a more structured approach than do novices, along with a more structured system understanding (Ball et al., 1997; Chi et al., 1988). Similarly, Von Gog et al. (2005) found that expert troubleshooters also spent more time on problem orientation (making an inventory of components and predicting system function) than novices, who were more likely to not perform any form of preparation, and instead immediately begin testing. They also stated that the lessexperienced are likely to pursue and stick with the first idea they come up with, whereas experts are more likely to evaluate a number of possible paths before travelling down any one. These characteristics are echoed by Chi et al. (1988), and also by Means and Gott (1988). In a field study of anaesthesiologists done by Xiao et al. (1997), the importance of preparation and anticipation is noted as an important element of expert performance.

Automaticity. Chi, Glaser, and Farr (1988) stated the experts have better short- and long-term memory than do novices due to the fact that they have automated many actions, and so have more resources available to them. Schneider and Shiffrin (1977) also found that much of expert thinking relies on automated processes. Both of these characteristics were reiterated by Chi (2006), where it is stated that experts can retrieve domain knowledge with minimal cognitive effort, and that they can execute their skills with greater automaticity. Finally, Feltovich et al. (2006) stated that automaticity is central to the development of expertise, in that basic skills must be automated before proficiency can be gained in more high-level skills, "such as reasoning, comprehension, inference, monitoring, and integration" (p. 53). They also echo the importance of automation in freeing cognitive resources to be focused on other activities. 
Although it is not certain that every one of these discussed expert characteristics is present in the expert performance of elevator and amusement device inspection, an exploration into these safety inspection tasks based on these characteristics of expert performance is likely to uncover important information about the content and organization of expert inspector knowledge. 


\section{Chapter 3. Method}

This thesis was designed as a qualitative study with the goal of creating a taxonomy of the knowledge that elevator and amusement device inspectors use when performing the inspection task. The explicit/implicit/tacit model of knowledge influenced the use of both task and cognitive task analysis in this thesis, with task analysis meaning to capture much of the explicit knowledge involved in the inspection task, and cognitive task analysis meaning to capture the explicit, as well as the macrocognitive implicit and, if possible, the tacit knowledge involved in the inspection task.

As such, the thesis consisted of two distinct parts: (1) task analysis and (2) cognitive task analysis. The cognitive task analysis itself was made up of three parts: (1) knowledge audit interviews, (2) initial data analysis, and (3) second data analysis. Figure 1 outlines the methods that were used in this research, and a discussion of how each of these was performed is provided in this chapter.

- Lack of domain experience

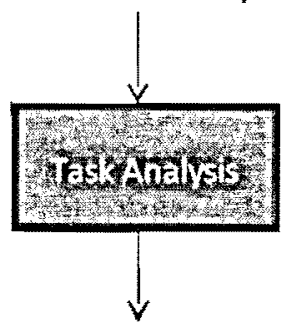

- Task analysis diagrams

- Domain orientation
- Portability and flexibility

- Broad, exploratory research

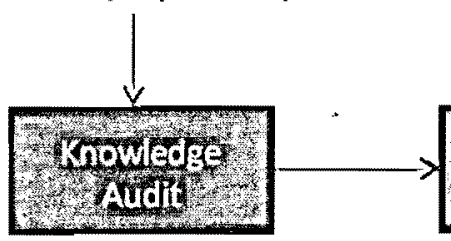

- Confirmation of expertise

- ID of main themes

- Led to application of new knowledge framework

Figure 1. Research outline 


\subsection{Participants}

Participant expert inspectors for both the task and cognitive task analysis portions of this thesis project were identified by inspection managers at the TSSA. These managers nominated inspectors for this project based on two factors: (1) that they were identified as being expert inspectors by their superiors, and (2) that they were located within the Greater Toronto Area (GTA). Participation in this research by these nominated inspectors was voluntary. All of the inspectors who participated in this project were both elevator device and amusement device inspectors.

\subsubsection{Task analysis}

Throughout the task analysis phase of this project, the researcher observed a total of 20 periodic hydraulic elevator device inspections with six expert inspectors, and a total of 17 periodic amusement device inspections with six expert inspectors. The task analysis models were developed concurrently with the observation of inspections, and observations were continued until no further changes were being made to the models.

\subsubsection{Cognitive task analysis}

As will be described in the sections that are to follow, the analysis of the cognitive task analysis data took place in two parts. The first consisted of a general analysis of the main themes raised for each of the characteristics of expert performance explored in the interviews. The second part consisted of the creation of a coding scheme that categorizes all of the knowledge employed by elevator and amusement device inspectors. It was this coding scheme that determined the number of interviews that were conducted for this research project. 
There is an abundance of knowledge in the elevator and amusement device inspection domain, and collecting all of this knowledge is impossible. The goal of this project, though, was not to collect all of the knowledge of expert inspectors, but rather to gather a wide enough pool of knowledge that would represent the majority of knowledge types used by inspectors.

The following graphs, shown in figures 1 and 2, illustrate the number of novel codes elicited in each interview. They show a trend of diminishing returns for each successive interview and increase the confidence that additional interviews would not have uncovered many additional codes that were not uncovered in the preceding interviews. A total of 83 codes were created, and are presented in the Results chapter of this thesis.

A total of seven Knowledge Audit interviews were conducted with seven inspectors who were expert at both elevator and amusement device inspection. Each interview was between one to three hours in length.

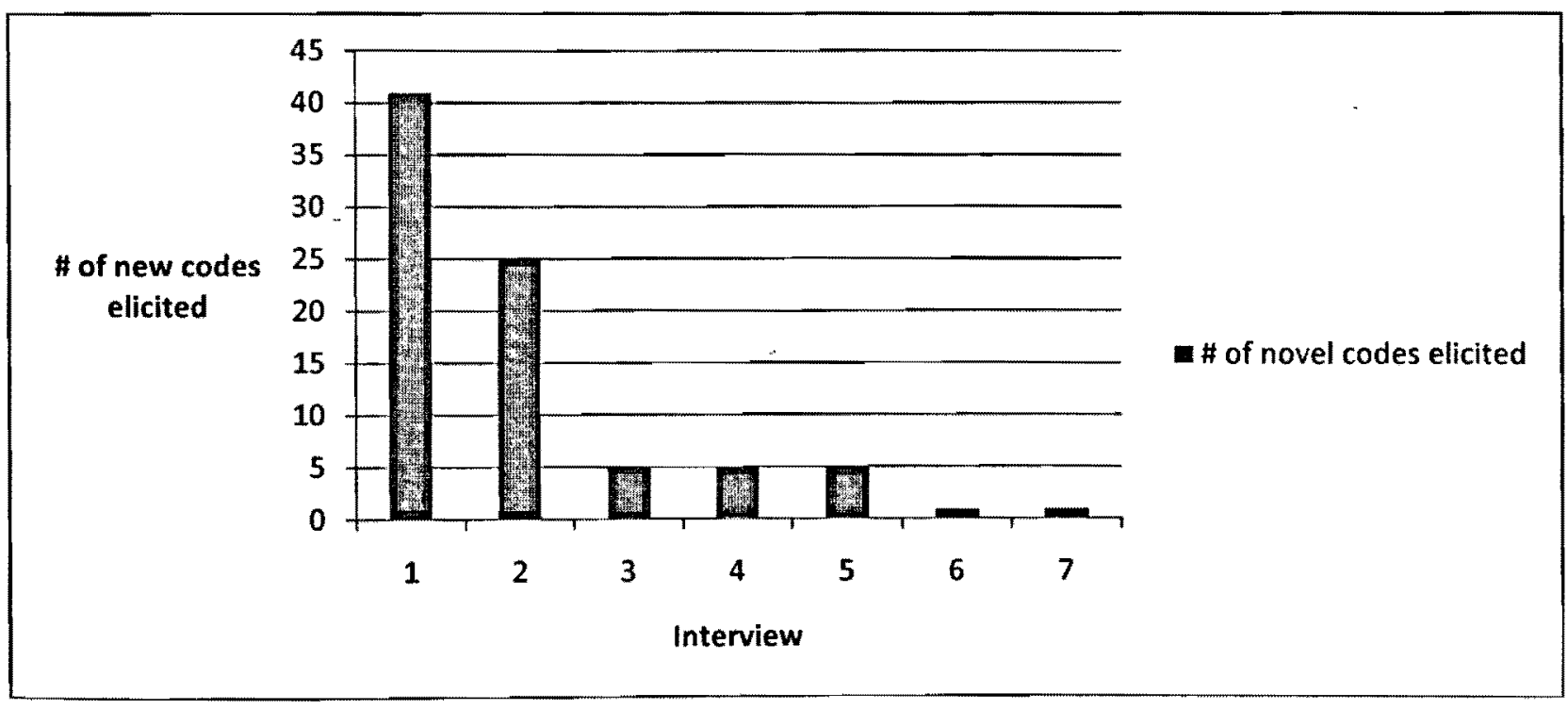

Figure 2. Number of new codes elicited per interview 


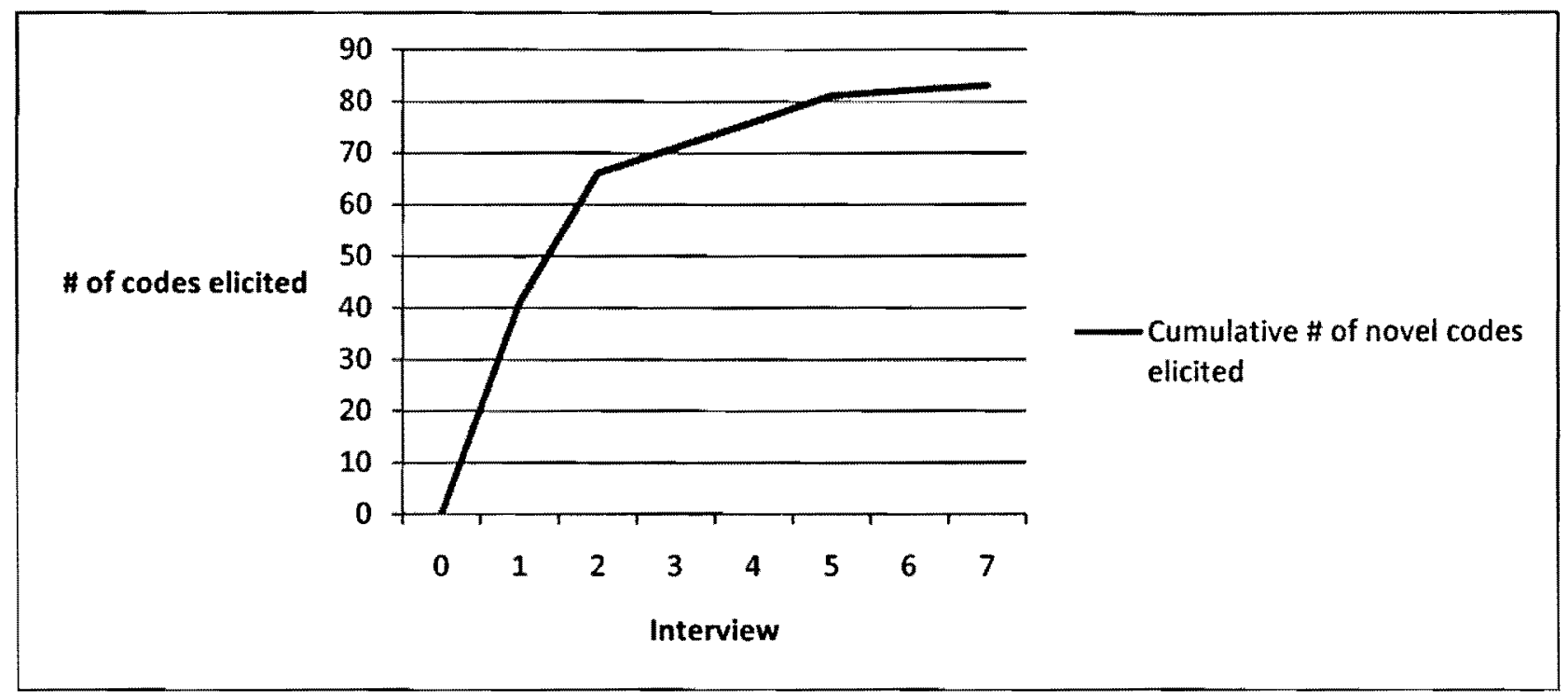

Figure 3. Cumulative number of new codes elicited per interview

\subsection{Task Analysis}

The first phase of this thesis consisted of a task analysis of the periodic inspection of both hydraulic elevators and amusement devices. The task analysis was performed to capture and model much of the explicit knowledge that is involved in the performance of the inspection task. Task analysis models of the expert periodic hydraulic elevator task and the amusement device inspection task were created through the observation of these inspections, along with in-situ interviews. The models were developed concurrently with the observations of these inspections, and were iteratively improved throughout this phase of the thesis. The models were then independently reviewed by four and three expert inspectors, respectively, in order to verify their representativeness of the inspection task. In addition, elements of the inspection task that required further description beyond the observations taken during the data collection for the task analysis were explored, such as any preparation that is performed prior to inspection and the process of writing inspection reports.

These task analysis models were initially intended to play a larger role in the creation of the 
knowledge models than they ended up playing. The reason for this, as will be discussed in the Discussion chapter of this thesis, was that inspectors do not think about the inspection procedurally as is represented by these task analysis diagrams. As a result of this, the primary contribution that the task analysis phase had in this research was in the domain orientation that it provided to the researcher.

Periodic inspections are only one type of inspection that amusement device (and elevator device) inspectors perform. Hydraulic elevators also only make up a portion of the types of devices that inspectors are responsible for inspecting. Unfortunately, due to safety concerns, the researcher was only granted permission by the TSSA to observe hydraulic elevator inspections, and due to the infrequency of initial hydraulic inspections, no opportunity arose for the researcher to observe an initial inspection. In spite of representing only a portion of the responsibilities of inspectors, the modeling of these inspection tasks allows for the investigation of the differences between these tasks and other inspection tasks, such as traction elevator inspections and initial inspections, during the cognitive task analysis interviews.

\subsection{Knowledge Audit interviews}

Whereas task analysis was performed to capture much of the explicit knowledge involved in the inspection task, cognitive task analysis was performed to capture the implicit (in addition to explicit) knowledge that is involved in the performance of the inspection task. The cognitive task analysis approach that was used in this research consists of the Knowledge Audit of the ACTA (Applied Cognitive Task Analysis) methodology introduced by Militello and Hutton (1998). An important aspect of human factors research is generalizing research that has been performed in one particular domain so that it is applicable across any number of domains, allowing general 
conclusions concerning human performance to be made (Xiao and Vicente, 2000). General, domain-independent knowledge is extremely important for our understanding of human performance, but in order to apply this general, domain-independent knowledge to other domains, a transition from general knowledge back to specific knowledge must be performed. This is the principle of the ACTA approach to cognitive task analysis, which makes use of general knowledge about expert performance to inform an efficient cognitive task analysis. In this thesis, the combination of real-world observation with structured Knowledge Audit interviews was intended to bridge the contrived nature of laboratory research to the unstructured and generally unsystematic nature of field studies and of the real world.

The cognitive task analysis was performed by investigating specific characteristics of expert performance that have been identified across a variety of domains in the expert-novice differences literature. These characteristics of expert performance were listed and discussed in the literature review chapter of this thesis. Each interview took between one to three hours, and an audio recording of each was made.

\subsubsection{Interviews}

The Knowledge Audit interview consists of a series of probe questions that are designed to capture "the most important aspects of expertise while streamlining the intensive data collection and analysis methods that typify studies of expertise" (Militello and Hutton, 1998, p. 1621).

The intent of using the Knowledge Audit interview was to collect a wide range of explicit and implicit knowledge concerning the major characteristics of expert inspector performance. In the Knowledge Audit interview, the researcher asked a probe question for each characteristic of expert performance in relation to both elevator and amusement device inspection, and the 
examples provided as answers to these probe questions were expanded upon by investigating the cues and decisions that played important roles in each example. Table 1 contains the Knowledge Audit interview probe questions that were used in this thesis.

Table 1. Knowledge Audit probes (Militello \& Hutton, 2008)

\begin{tabular}{|c|l|}
\hline Expert characteristics & \multicolumn{1}{|c|}{ Probe questions } \\
\hline Past \&. Future & $\begin{array}{l}\text { Is there a time when you walked into the middle of a situation and knew exactly how things got } \\
\text { there and where they were headed? }\end{array}$ \\
\hline Big Picture & $\begin{array}{l}\text { Can you give me an example of what is important about the Big Picture for this task? What are } \\
\text { the major elements you have to know and keep track of? }\end{array}$ \\
\hline Noticing & $\begin{array}{l}\text { Have you had experiences where part of a situation just "popped" out at you; where you noticed } \\
\text { things going on that other didn't catch? What is an example? }\end{array}$ \\
\hline Job Smarts & $\begin{array}{l}\text { When you do this task, are there ways of working smart or accomplishing more with less-lhat } \\
\text { you have found especially useful? }\end{array}$ \\
\hline $\begin{array}{c}\text { Opportunities/ } \\
\text { Improvising }\end{array}$ & $\begin{array}{l}\text { Can you think of an example when you have improvised in this task or noticed an opportunity to } \\
\text { do something better? }\end{array}$ \\
\hline Self-Monitoring & $\begin{array}{l}\text { Can you think of a time when you realized that you would need to change the way you were } \\
\text { performing in order to get the job done? } \\
\text { Can you describe an instance when you spotted a deviation from the norm, or knew something } \\
\text { was amiss? }\end{array}$ \\
\hline Anomalies & $\begin{array}{l}\text { Have there been times when the equipment pointed in one direction, but your own judgment } \\
\text { told you to do something else? Or when you had to rely on experience to avoid being led astray } \\
\text { by the equipment? }\end{array}$ \\
\hline Equipment Difficulties
\end{tabular}

Patton (2002) was used as a primary reference in preparing for the remaining details of the interview process, which are as follows:

Support and recognition responses. According to Patton (2002), "a common mistake among novices is failing to provide reinforcement and feedback" (p.375). "Words of thanks, support, and even praise will help make the interviewee feel that the interview process is worthwhile and support ongoing rapport" (p. 375).

Maintaining control and enhancing the quality of responses. Patton (2002) states that "control is facilitated by (1) knowing what you want to find out, (2) asking questions to get relevant answers, (3) listening attentively to assess the quality and relevance of responses, and (4) giving appropriate verbal and nonverbal feedback to the person being interviewed" (p. 375376). 
The closing question. It is important to allow the interviewee the opportunity to bring up any other points that he perceives as relevant to the topic and domain, but that weren't covered in the interview. Patton (2002) suggests two questions that can achieve this end: (1) "That covers the things I wanted to ask. Anything you care to add?" and (2) "What should I have asked you that I didn't think to ask?" (p. 379).

After the interview. As soon as possible following the interview, the recordings were reviewed and transcribed, and if any clarifications were required, they were recorded and e-mailed to the interviewee. This post-interview transcription period was also used to assess the quality of the responses, and identify whether any aspect of the interview could be improved for the following interviews.

\subsubsection{Transcription}

Transcription was performed using Transcriber $^{1}$, which is an open source program that assists in the manual annotation of speech signals. The transcription of each interview consisted of three stages. In the first stage, the interview was played through the Transcriber program, and dividers were placed throughout the audio track, which separated the track into sections of three to ten seconds in length. In the second stage of the transcription process, the interview was again played through the Transcriber program, section by section, and was manually transcribed. In the third and final stage, the interview was again played through in its entirety while the written transcript was reviewed for errors.

\footnotetext{
${ }^{1}$ http://trans.sourceforge.net/en/presentation.php
} 


\subsection{Cognitive task analysis}

\subsubsection{Identification of the characteristics of expert performance}

The initial analysis of the Knowledge Audit interview transcripts consisted of an initial pass through the interview data that was guided by the characteristics of expert performance that were the subject of the interviews.

The approach to data analysis that was employed in both the initial and second analysis of this project was a combination of deductive and inductive analysis. In this initial analysis, each interview transcript was coded using the ten expert characteristics that were discussed in the literature review chapter of this thesis. Once this coding had been completed, the major themes of each expert characteristic were identified through inductive analysis. Multiple readings of each expert characteristic across all of the interviews was performed, and each time that a potentially relevant theme to a specific expert characteristic was identified, it was recorded. As new potentially important themes were uncovered during each successive reading of a transcript, the previous transcripts were re-read in light of these additional themes. If any theme was found to be recurring across a number of interviews, it was identified as being an important theme requiring discussion.

\subsubsection{Creation of taxonomies of expert inspector knowledge}

This second analysis of the Knowledge Audit interview transcripts consisted of a more in-depth analysis of the structure of the knowledge that expert inspectors use while performing both elevator device and amusement device inspections. Like the initial analysis, it consisted of a combination of deductive and inductive analysis. 
Each transcript was read through two consecutive times, and sections of the interviews where expert inspectors referred to their knowledge were highlighted and then extracted into an Excel spreadsheet. Once all of these extracts were collected into one data sheet, they were coded as being either declarative, procedural, or strategic knowledge. If an extract contained two or more types of knowledge, it was coded as such. Once the transcript extracts had been divided between the three knowledge groups, a summary of each extract was made, and then further categorized into either general, amusement device, or elevator device knowledge.

Following this, a categorization of the knowledge extracts in each knowledge group was developed inductively through an iterative reading of the raw data. This process was performed for each interview transcript. Naturally, and particularly for the earlier transcripts, the coding scheme for each of the knowledge categories changed after each successive reading of a transcript, with new categories being added, other categories being combined, and some categories being changed or removed altogether. Each time a change was made to the coding scheme, the previous transcripts were re-analyzed to conform to this new scheme and to ensure that any changes made to the coding scheme due to any one interview transcript was applied uniformly to all other transcripts. This process was performed until a final coding scheme emerged that represented a taxonomy of all of the knowledge elicited from inspectors during each of the interviews.

\subsubsection{Structure of the resulting taxonomy}

The final coding schemes/taxonomies resulting from this process are described and presented in the Results chapter, and in Tables 3 to 7 . The taxonomy was designed to allow for the description of the entire range of inspector knowledge, from detailed device-specific knowledge, to the high- 
level strategies that inspectors use while performing an inspection. It was designed not just with knowledge representation in mind, but was also designed with consideration put towards the navigation through the collection of knowledge coded by this scheme. In other words, an attempt was made to design a taxonomy that was both representative of the process of device inspection, but also functional if trying to find specific information concerning the inspection task.

Of course, it will not be desirable, or even possible, to capture all of the knowledge represented in the taxonomy. Theoretically though, if the entirety of expert. inspector knowledge was captured, this taxonomy would provide a functional means with which to organize and label that knowledge. This was identified as being an important aspect of the taxonomy, because even if all of the information cannot be captured, it is important to understand the structure of that knowledge, and understand how it is used by inspectors. 


\section{Chapter 4. Results}

This chapter presents the results of this thesis in four parts. First the results of the task analysis are presented. This is followed by a presentation of the results of the initial interview data analysis, and then a presentation of the results of the second interview data analysis. This chapter concludes with a presentation of some of the most important differences between amusement and elevator device inspection.

\subsection{Task analysis}

\subsubsection{Task analysis of expert hydraulic elevator inspection}

The task analysis of periodic hydraulic elevator inspection was based on the observation of six expert inspectors performing a total of 20 periodic hydraulic elevator inspections. Inspectors were identified as being experts by their supervising managers. The task analysis that was developed based on these observations was then reviewed and verified by four expert inspectors. Fig. 4 contains the high-level tasks of the periodic hydraulic elevator inspection task. The complete task analysis diagram for this task can be found in Appendix B.

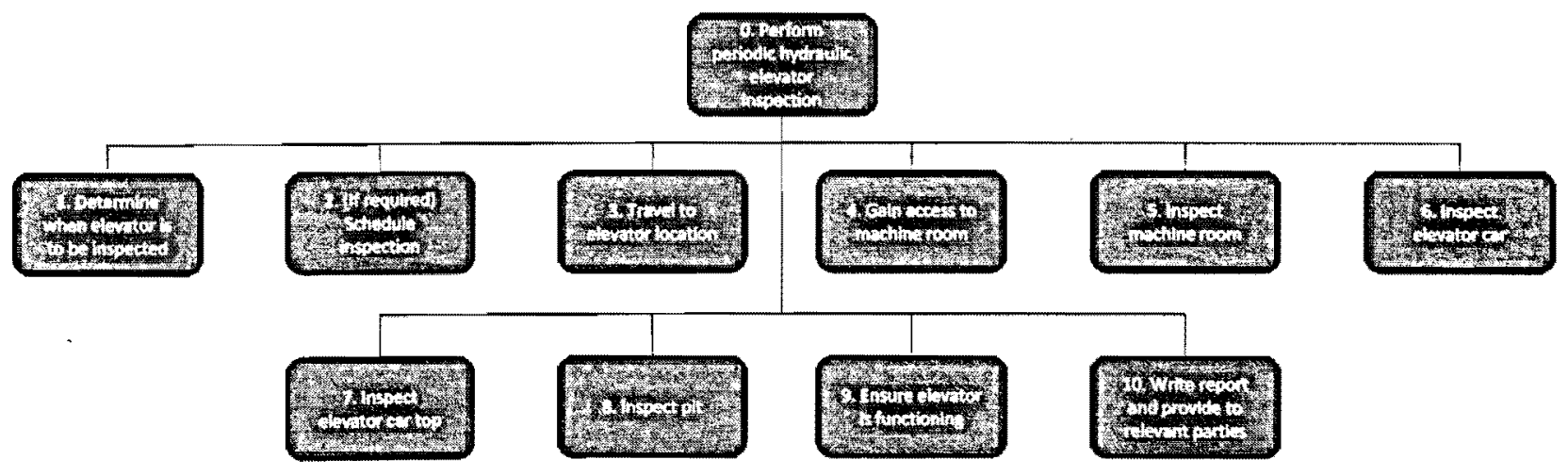

Figure 4. Top level of periodic hydraulic elevator inspection task 


\subsubsection{Task analysis of expert amusement device inspection}

The task analysis of periodic amusement device inspection was based on the observation of six expert inspectors performing a total of 17 periodic amusement device inspections. As with elevator device inspection, experts were identified as being expert by their supervising managers. These task analysis diagrams were reviewed and verified by three expert inspectors. As will be presented in the Discussion chapter, due to the nature of the amusement device domain, the task analysis diagrams for the amusement device inspection task are more general than those of the periodic hydraulic elevator inspection task. Fig. 5 contains the high-level tasks of the periodic amusement device inspection task. This task analysis diagram can be found in Appendix C.

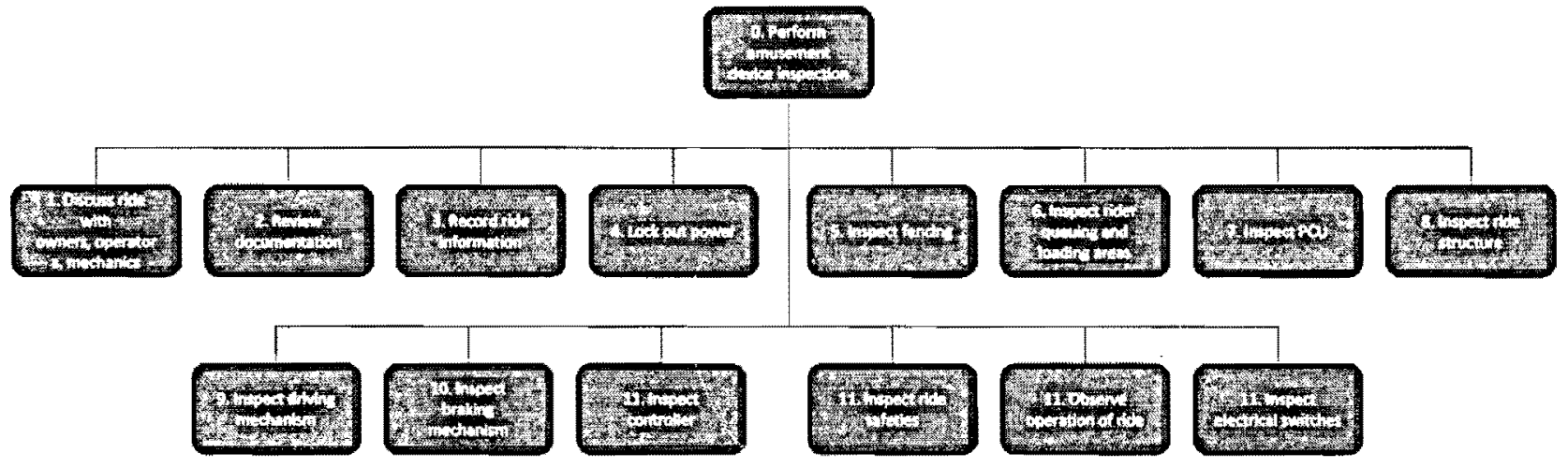

Figure 5. Top level of amusement device inspection task

\subsection{Characteristics of expertise in the inspection task}

The initial data analysis accomplished three things. First, it confirmed the existence of expert performance in the elevator and amusement device inspection domain. Second, it resulted in an identification of some of the main themes surrounding expert performance in the domain. Finally, it led to the application of the strategic/procedural/declarative model of knowledge in the creation of the taxonomy of expert elevator and amusement device inspector knowledge. 
The following section presents the major themes of expert inspector performance identified in the initial analysis of the Knowledge Audit interviews. It is divided into the major characteristics of expert performance that were discussed in the literature review chapter of this thesis and that made up a majority of the probe questions used in the Knowledge Audit interviews. For each of the characteristics of expert performance, the major themes that were identified during the analysis of the interview data are presented in relation to their importance to the inspection task.

\subsubsection{Big picture}

When discussing what knowledge was most important for the big picture of the inspection task, two types of knowledge arose most frequently: (1) specific device knowledge of components, accidents, and experiences, and (2) 'confidence', 'common sense,' and the inspector's ability to think critically about the device and the inspection. When it comes to specific device knowledge, inspectors are required to know what the different components of a device are, how those components work together, indications of their condition, how they fail, how users interact with them, etc. The following interview extracts illustrate the importance of this specific device knowledge that inspectors at the TSSA currently gain primarily through experience-

"But you got to know, also. I would not check something that I don't know of. I've probably missed things too. But if I don't know of what a hazard is, I wouldn't check for that hazard. One of the important things is to give people the knowledge of these are the potential hazards and the way you check."

"So if somebody tells you that, or you had to investigate an accident, guess what? You'll check that every time. So you have to know. So some information has to be provided. Or else it'll take a very long period for you to find out. Or you may not even know if you haven't had to investigate those things. So knowledge is very important."

Just as important as specific device knowledge is the inspectors' ability to understand how to think critically about a device, and what questions to ask and what strategies to follow in order to 
find all of the hazards contained within that device, such as when inspectors inspect a device from the users' perspectives, when they assess the maintenance a device is receiving, and when they communicate with both users and with the people involved in the maintenance the device.

The application of this 'common sense' or critical thinking was highlighted throughout the interviews-

Inspector: "There might be things that I've inspected that didn't pop out at me, but might pop out at another inspector. So it works both ways."

Interviewer: "Why do you think that is?"

Inspector: "I think it's got to do a lot with your experience, with how your work and working experience and things that have occurred during your experience, basically. And also your understanding of issues, like how, when you look at an issue, how do you rate that issue? Like you decide, 'Okay, this is a serious issue, you must look at it'. Versus somebody who's instructed, 'Okay, this is the bulletin that's issued, and this is what happens, so it's got to be rectified.' If you don't understand the full implications of it, then you're not going to be specifically looking for it."

"So that's sort of the big picture vs. the specific, you know, what type of building am I in? Who's going to be exposed to this hazard? Does it really matter? Yes by code, in both cases, it doesn't meet the code, but in one case it's very severe because it's in a mall or a school or whatever, and in another case because it's in an office building, people don't go up to the door and put their hands on the elevator doors waiting for it to open, right? So it's not that much of an issue and the maintenance it's getting is pretty good, so you may give it a longer time limit."

\subsubsection{Principled and systematic approach}

As discussed in the previous section, 'confidence' and 'common sense' make up one of the most important aspects of inspector performance, and both terms were brought up frequently throughout the interviews-

"[...] because even though you know the steps and you have the checklist and go through it, it does take you a while to get that comfort level. And then as you're more confident with your inspection, you feel more confident questioning things."

"They don't want to make decisions, they're going to phone for decisions. They've just got to make common sense. If you think about something a little bit further down, the ramifications, you can't make your own answer, but a lot of guys won't make their own 
decisions on things. Use some common sense."

Both 'confidence' and 'common sense' are simply different words for knowledge. They are an inspector's ability to effectively inspect for safety hazards and to perform the safety hazard assessment of identified safety concerns. Examples of this type of knowledge are an inspector's ability to assess the environment and identify safety concerns, their ability to understand the role of device components and their relationship to the ultimate safety of a device, and their ability to understand the likelihood and potential outcomes of the failure of that component in relation to the environment in which it's found.

All of these 'common sense' tasks that inspectors perform suggest inspector knowledge that goes beyond just specific device knowledge and beyond the structure of the inspection task as detailed by the task analysis diagram. The task does not simply consist of inspecting a fixed number of components and comparing those to what the code says about them or to specific device knowledge that the inspector has about them, instead they are frequently making decisions and questioning the code-

"That comes with times there too, they've got to eventually learn to make a decision themselves, there's so many decisions you make on your own."

"On a day-to-day basis, we're constantly questioning the code."

An expert inspector's 'common sense' plays an important role in a successful inspection by expanding the structure and task flow of the inspection task from the almost checklist-like approach (as represented in the task analysis diagram) to a more dynamic, goal-directed approach. A further discussion of the importance of 'common sense' knowledge can be found in the Discussion chapter of this thesis. 


\subsubsection{Noticing/anomalies}

Two main themes were evident when discussing inspectors' ability to notice cues and anomalies, and these were (1) the importance of experience, and (2) information overload.

\section{Importance of experience}

All the interviewed inspectors stressed that experience is important in detecting cues, seeing meaningful patterns, and identifying what is atypical in a device-

Inspector: "It's just more of the stuff that's more experience that will basically give you the extra knowledge and stuff, 'maybe I'd better check into that, something's wrong, I'm not sure what it is, but I feel that something's going to be wrong.' That basically comes down to experience. You can't read a book on that. You won't find it in a textbook. You can't even really teach the people unless you go out with them and give them hands on experience."

Interviewer: "Do you find that there's a lot of knowledge like that?" Inspector: "Oh there's a lot, especially in elevators and amusement rides."

"I think as an inspector, it takes you at least four years to get the real hang of it, to get into a comfort zone of what you want to look at."

And experience is important not only because of the specific device knowledge that inspectors gain from it, as discussed in an earlier section, but also because of the development of general knowledge that experts make use of during inspections-
"So if you're an expert in electrical, then you can ask a whole bunch of electrical questions, because that's your strong point. [...] not all inspectors have the same knowledge. Some guys might be strong in hydraulics, some guys might be strong in pneumatics, and some guys might be in welding. So if you're a welder, you might ask welding questions. But if you look at the rides, they're a whole bunch of combinations of all these things. So it takes time to beef up the other areas. Everybody has their strong point, but the other areas, it takes time know how they work."

But while experience was identified by all inspectors as being essential in the development of their knowledge and the effective performance of their inspections, the experiences that any one 
inspector may have can vary widely from the experiences that another inspector may have-

"Experts are experts. And no two experts are the same. I'm a human, we see things based on our experiences. So I might go do an elevator, and I might completely go and do a good job, and somebody else with a whole different set of experiences might come along and find $a$ whole series of... [...] But that person might find something different based on their knowledge and experience."

This variety in experience between inspectors was also provided as the primary cause for there being a lack of consistency between inspectors. The variety in experiences that each inspector has accumulated over their years of experience has lead to a latge difference in specific device knowledge between them-

"Because you can't know everything. There's no way on earth, I don't care who you are [...]. I don't know everything, and you can't know everything. Codes they change and rules change, you can't keep up with them. It's impossible. They scream about consistency among inspectors. You're never going to get 100\% consistency among inspectors."

"Sometimes they're not aware of certain issues, so yeah, constantly, we keep finding stuff that has been missed in the past and that stands out to you."

In spite of this variability in the experiences and performance of each inspector due to the essential role that the knowledge gained through experience has in the performance of inspections, the communication of knowledge between inspectors through the sharing of experiences appears to be minimal. Some amount of that knowledge may be communicated to trainees during on-the-job training, but the amount that is transferred is likely minimal in relation to the total amount of knowledge that each inspector has gained over their career. Once an inspector is out of training, the opportunities for information sharing between inspectors are infrequent-

Interviewer: "So do you get the opportunity to speak to inspectors a lot?" Inspector: "Not too much. Not as much as we would like to, because we're so busy with our work. The odd time we do meet... probably we meet once a month. And there's hardly any time to discuss issues." 


\section{Information overload}

For elevator device inspection, inspectors are required to retain a large amount of information in order to perform inspections effectively. One of the main forms of knowledge that inspectors are expected to retain is that of the device codes, and not just the most current iteration, but previous iterations as well, due to the fact that if a twenty-year-old device has never been modernized, then it must only adhere to the code that was active during its installation. The difficulties in memorizing the code is illustrated in the following interview extracts-

"I've gone through 25 years and I've gone through about 10 different code books, and the first six of them I know inside and out, the last 2 or 3, you don't know them quite as well unless you encounter. them, and a lot of times they'll come up with a new rule that you never read, you never heard about it, and then you're maybe with a trainee or a new guy and they say, "Well what about this rule?" I didn't even know that rule came out, and it came out two years ago. I didn't even know that rule was there. That happens all the time. Unless you encounter that rule. And you can't, like I said, you've got a book like this, four inches thick. And they might come out with 100 new rules, and you might flip through them and see them, but you're not going to remember them all unless you have a specific problem in the field where you've got to look for that problem, then you're going to pick it up. You can't remember it all, there's no way. But general common sense points in the right area. You just know if something is right or something is wrong. You don't know the specific rule."

Interviewer: "So it's not exactly that you have to have memorized the past ten or twenty codes?"

Inspector: "No, it's impossible."

In addition to the code, inspectors are also expected to be aware of every device bulletin, which are manufacturer-released documents that call for a retrofitting of specific devices, that has been released for the collection of devices throughout their region-

"The manufacturer's bulletins and the various orders that keep coming out, it's like... and you asked me how you keep track of it. It's either through knowledge or through training. A lot of it, at times, you're depending on your memory, basically. You've been told, 'Okay, you've been given 20 issues, that exist with twenty different types of equipment, now you have to remember each issue.' In fact I was with another inspector when I was doing that, 
and he didn't see it, and I pointed out to him, and he didn't know that existed, and I told him. I pulled it up from the old files and showed it to him, and he was still not satisfied. He said, "There's no way seven inspectors would have missed it." But that's the nature of it."

The memory requirements described above regarding knowledge of the elevator code and device bulletins are just a portion of the knowledge that an inspector is required to possess. In addition to these, the inspector must also possess knowledge about the various devices that they inspect, such as the peculiarities of devices made in particular eras by particular manufacturers, knowledge about health and safety during the inspection task, and knowledge about the users who use those devices-

“And you can't know everything, this business is just... there's so much to learn, and there's so many different companies. [...] you might go fifteen years before you even see this particular problem or company or whatever."

In spite of this information barrier, expert inspectors manage to largely overcome it, but for novices, this barrier will seem overwhelming. Many inspectors echoed the sentiment that inspector training can only provide a small amount of preparation and knowledge required to perform as an expert inspector-

"[...] when you're on your own, you've got to make all your decisions yourself and when you screw something up or get it broken down you've got to think twice as much. So it's hard. You learn a lot more the first six months you're out alone in your own district because you've got to make all your own decisions, deal with all your own paperwork, organize everything yourself. That they can't teach it to you."

"A good inspector graduating from our training program, if he says he's an expert, under 10 years, he's telling you a lie."

Amusement device inspection has similar, but potentially even more difficult memory requirements, and these will be discussed in the discussion of the differences between elevator device and amusement device inspection, which can be found later in this Results chapter of this 
thesis.

\subsubsection{Job smarts and automaticity}

Examples of 'job smarts' were evident in all aspects of the inspection task. These consist of heuristics and automated strategies that inspectors use to assess the state of the device, to inspect particular components, or to make their inspections more efficient, effective, or safe.

One of the strategies that inspectors use to is identify and focus on the areas of the device where mechanics regularly perform maintenance-

"[...] there are mechanics that go there and perform maintenance every month. Where do they go and perform their maintenance? They perform maintenance on the doors, and they perform maintenance in the elevator machine rooms. People are liable to make mistakes. Because if nobody goes there, you'll assume that nothing has changed and it's safe. But once people are performing a task, you got to look at the areas where they're performing that task."

Another strategy that inspectors use is to look out for any modifications that have been made on the device, and assess the quality of those modifications and the effect that they might have on the device as a whole-

Interviewer: "So do you find that you do that a lot, that as you go through a ride, you keep an eye out for things that have been changed, things that have been modified in order to guide your inspection?" Inspector: "Yes, I do. And I question it."

A third strategy inspectors use to assess the maintenance a device is receiving is to speak to contractors about bulletins, assess whether they are aware of the bulletins, whether they have addressed the bulletins, etc.-

"[...] we do have the bulletins too. So we will know where's the most risk and we will ask them or watching them, see if they already changed that part, or if they are still using the original manufacturer's parts. Then we will know whether they are well maintained or if they are following the instructions or not." 
All of the above are heuristics and strategies that expert inspectors use to assess the maintenance that a device is receiving. Inspectors also use heuristics to achieve lower-level, explicit goals, such as those found in the task analysis diagram, for example: "Inspect track", "Inspect nuts and bolts", or "Inspect cable". One of the heuristics that inspectors might use is to assess the environment surrounding a component, and look for any stresses that the environment may be placing on it-

"So if you have a more experienced inspector, they may look up the hoistway and they notice as they're going up that there's a ventilation duct or a vent opening into the hoistway and the hoist ropes are right in front of it, so now if the elevator normally parks at the ground floor, that part of the hoist ropes that end up in front of the vent, when the elevator is at the ground floor, is going to be subject to that moving air and moisture and all that all the time."

Inspectors also might not always inspect every aspect of every component. Occasionally, inspecting components from a high-level perspective may make finding indications of defects easier-

"[...] you can look at something and go across it and something jumps out at you. There's a hundred things there, and there's just one of them that's different. You don't have to go through each one of them individually, you can just take a general glance at it and say there's something that jumps out at me, there's something different about that, and then you take a closer look at it. Maybe it's broken, or it's not attached, or the bolt's loose."

In addition, inspectors might have specific techniques that they use when inspecting particular devices components-

"[...] newer inspectors, they actually stop the elevator at the door and they open the lock, and they see how much it engages, and they try to pull it open and see that it's still locked, and then they try to run the elevator and then they let the lock move down until the contact makes up and then they see that, oh, it's still locked, and now they can actually stop again and then look at the rest of the door. Where you see somebody with a lot more experience as the elevator is moving on inspection speed going past the door, they grab the lock but they don't quite squeeze those rollers together to lift the beak, they lift it just slightly and the elevator stops, and they give the door a shake and they see that 
it's locked, but that shake also tells you how much play you have in the door, if the door eccentric rollers are adjusted properly so the door isn't shifting too much, that the clearance is probably not too much because the play back and forth wasn't very much. So just shaking the door once sort of gives you the idea that this is a pretty solid door, everything is nice and tight, clearances should be alright, and also you stopped the elevator while you were moving down just once, checked everything you had to check and then you continue to the next door, where a novice inspector may have to move and stop the elevator two or three times to check one door."

'Job smarts' comprise not only the strategies that inspectors employ when inspecting for deficiencies in the device, they also comprise how they navigate through the device space. These can include strategies to make the inspection more efficient, such as effectively catching a specific elevator that needs to be inspected in a building with multiple elevators, or organizing tasks in such a way that the inspection takes less time than it otherwise would-

"I find this quite often with novice inspectors. They've inspected two of the elevator in a building that has three elevators, so two of them are inspected, and they're trying that third elevator to inspect it. Usually what I do is if I'm about to finish with one elevator and I still have it on inspection, I'm about to get off, I take a look down the hoistway to see where the other two elevators are and which one do I need to get? So while this car is still on inspection and the doors are open--it's not on automatic service--I'll put a hall call in knowing that I'm calling on of the other two elevators now, and if I see that the elevator is coming up to answer the call is the one I've already inspected, I'll actually wait for it and not put the centre elevator into service, wait for that elevator to come, and I'll put a call to the bottom floor, let it go, and I'll put another hall call in. Now the third elevator that I haven't inspected is the only choice left, that one has to answer this call. So I see that it's starting to come up, then I can finish with this elevator, put it back into service. By the time I'm done, the other elevator has reached the top floor and now I can get on top of that one and do my work. Where I find that a novice inspector will finish his thing, get off, all the doors are closed, all three elevators are running, and now they push the button and they wait for the elevator, and they get the elevator they just finished looking at, and they have to send that away, push the button again, and then they get the other one and then the elevator they haven't inspected may be sitting at the bottom on service because the cleaner has it, but they never paid attention to that.

"[...] to be efficient in the process, you check all the doors on the way down and you check all the hoist ropes on the way up, rather than checking the door then walking to the back of the elevator, putting yourself in harm's way, and then walking back again to the front."

- or strategies of how to assess and avoid the dangers inherent within the inspection task- 
"It's the same thing with amusement devices, the thing is swinging around. You want to make sure you're not in that area where the swing is. Parts are moving around. So that's why it's the same thing, by experience. You want to run the ride for a moment, you get familiar with what the thing does. Because some of these new rides they do different things that you didn't realize they do."

"I try to avoid the peak time, when I have to inspect the pit, pit equipment. Because I have to open that main floor door, [...] but when I get down in the pit, I have to keep the door open, at least for the time when I get down to the pit, basically. And people are so inquisitive, they want to come and peek and see what's happening. And I'm more paranoid about them falling into the pit."

The 'job smarts' of expert inspectors play a role in all aspects of the inspection task and represent an important aspect of expert performance.

\subsubsection{Past \& future}

Prediction into the past and the future is an activity that inspectors perform most frequently when performing risk assessments on deficiencies that have been identified during the inspection, and is an important aspect of their ability to think critically about the performance of a device. An inspector's ability to do this largely depends on, as discussed in a previous section, the inspector's experience and 'common sense'. When performing a risk assessments on a hazard that has been identified during the inspection, inspectors make use of their experience, such as knowledge of past accidents, or their knowledge of hazard indications, such as rust and cracks, and the impact that those indications might have in a variety of situations. Inspectors also perform higher-level critical thinking, such as the identification and assessment of the users of the device-

"[...] they should have taken something out of service because of the type of building it's in like in the case of the elevator in a shopping mall. Where you write it up and give it 30 days in an office building, in a shopping mall, you really have to get it addressed right away."

-the assessment of the quality of maintenance the device is receiving- 
"Big picture is that these are regular maintenance items. If that's all I found in a 30storey building then the maintenance company is doing a pretty good job, and I bet you even if I don't write them, they're going to find these on their next visit and change them"

—and the evaluation of any components in question, which involves activities such as the assessment of the role of the components in question (" $[.$.$] anything like that that you may find$ defective you really have to assess its job"), identifying whether those components have backups ("If this is going to fail, is there something to back it up?"), and identifying how long a device could function before a part is replaced ("If it breaks now, can I leave it for a while?").

\subsubsection{Opportunities/improvising and self-monitoring}

One of the main areas in which inspectors occasionally have the opportunity to improvise is in the performance of initial inspection tests. In discussing these tasks, inspectors frequently referenced the importance of assessing the goals of the tasks and the methods used to achieve those goals-

"If the device doesn't work, sometimes tests are written in a language that, if you actually do it by what it says, it won't work. So that's when we improvise in the field and say, 'What's the intent of the test?' Did the engineer mean this? So that's where your ability to play around with the language and understand why the test is being done."

"Well we do that electrical redundancy tests on initials all the time. The engineering will write it one way to do it this way, and it might tell you to jumper this, that, and the other thing there, and why don't I just hold the relay in? That does the same function. [...] If I can see it in my own mind, what is that jumper doing. [...] So if it's going to take him ten minutes to power off and rewire, I'll say, 'Why don't you just hold this in, it takes you two seconds and it does the same function.'"

These examples represent not just the ability to improvise, but also the ability to identify the opportunities in which to do so. Being able to do this requires that inspectors constantly ask questions and look for ways of improving procedures and inspector performance. This characteristic of successful expert inspectors was identified in other tasks as well, such as in the 
troubleshooting of devices that have stopped functioning properly during inspection-

"Well you want to find out why it's not working. When something doesn't work, I don't walk away, I want to know why. What did I do? What has caused it?"

"Once you've screwed up, how to turn it back on or recycle it or get it running again is a big thing from experience. Once you've screwed it and play around a little bit, you can fix it. Depends on your experience. If you've got a bit of elevator experience over the years, you don't mind going through the drawings, "Oh, I'm on the final, I've got to jump out the final limit." [...] Other guys will say, "It's broken, I'll call the mechanic. I'll wait an hour and he'll come in and, if I'm lucky, he'll fix it." If I break something, I try to fix it. If I can't, after I've wasted 3/4 of an hour, then I'll call the guy in."

This characteristic of constantly asking questions to yourself and to others about the device and its operation applies, in fact, not just to specific inspection tasks, like initial inspection tests and troubleshooting, but to all aspects of the inspection-

Inspector: "I always dig deep into it." Interviewer: "So we kind of talked about this before, but why is it that you always want to dig deeper?"

Inspector: "I guess that's my habit. That's me. [...] I don't accept anything, if somebody tells me something, I have to research it and be convinced of it myself."

"So when I went to investigate it, the mechanic tells you that this is what happened, [...] just because the mechanic has told you this is what happened, you don't just take his word for it, you want to look at every aspect of it."

This characteristic goes beyond even the inspection task to the stance that inspectors' take on their continued learning. Being able to identify gaps in knowledge, and the willingness to address those gaps is essential in the growth of an inspector's knowledge and his skills-

"And then if you are curious enough to find out why these tests are being done, Then you understand the control system better. When you understand the control system better, you get a better feeling for the elevator, and what would happen if that failed and those components failed. And that's how you build up your knowledge."

"Again, it's up to the person, because if that person just goes through these procedures just as a routine and not learn from them, and does not question himself and the mechanic as to, 'Hey why are you doing this? What would happen if...?' Then it's a procedure anyways, it really doesn't matter, you're just going through the motions. It is up 
to the individual to enhance their knowledge and understanding, and give them the confidence."

In fact, a majority of inspectors identified that interacting with mechanics and being given the opportunity to ask them questions was the most important learning resource available to them-

"[...] we're fortunate here downtown that we have a lot of new elevators coming up so we always dealing with new equipment, so we talk to the mechanic, 'How do we do this, how do we do that? When the doors are closed, how do I generate a call?,' And they tell us, basically. So that's one thing. And the other things is when you're just generally talking to a mechanic, 'Okay, how do I do this?'”

"[...] you've got to be fortunate to be able to witness initial inspections [...]. And in those days, I was in an area where there were no new devices coming up, so basically you're just doing periodics, and I used to do the subway system, escalators, which was great for me because that way an escalator is an inspection that is carried out with a mechanic, so you can go through stuff, and as they get to know you, the guys share knowledge and stuff as anybody would do. But you really start to think and get to know about an elevator system when you do a brand new inspection."

The ability of inspectors to assess the gaps that exist in their knowledge base requires that inspectors are able to assess themselves, their knowledge, and their performance, and this closely relates to the inspectors' monitoring of their own performance, which is essential to following some of the higher-level 'common sense' strategies that inspectors employ, such as never jumping to conclusions, never making assumptions about the previous state of a device, and also being aware about level of their own inspection performance.

Interviewer: "So how come you caught that and--"

Inspector: "I don't know. It could be that people assume that when it was initially done, it was tested and was okay."

“We can't say, 'It's raining and I'm going to rush.' or 'It's too cold, I'm going to take a quick look.' You just got to do what you have got to do. Put on extra clothes, put on extra protective equipment, be there by yourself. For me, the outcome at the end is most important. Forget the stresses or whatever. I try to focus on the safety, the end outcome which is it safe."

"As you get older too, you can't bend and twist, so you have to come up with means to... 
you can't compromise inspection, so you've got to find ways of doing the same thing in other ways."

Self-monitoring and identifying opportunities for improvement-not just of the inspection tasks, but also of the inspectors themselves - is a basic philosophy that ran through all of the interviews that were conducted. Nearly all of the inspectors expressed a philosophy of constant questioning and constant improvement, and this spread throughout all aspects of the inspection task-

"[...] some people get bored with the job too. It's the same thing maybe all the time, but I keep telling people everyday it's a different job. Everyday you're going to find something different [...], each product is different."

\subsubsection{Summary of expert characteristics}

In this section, the major themes of each of the characteristics of expert performance addressed by the Knowledge Audit interview were presented. For the 'Big Picture' of the inspection task, (1) specific device knowledge gained through experience and (2) 'common sense' critical thinking were identified as being of the utmost importance. 'Common sense' critical thinking was found to contribute greatly to the 'Principled and Systematic Approach' that inspectors took in performing inspections, by allowing inspectors to move beyond the checklist-style approach to inspection as represented by the task analysis diagrams to a higher-level goal- and questiondriven approach to inspection.

In discussing 'Noticing and Anomalies' inspectors frequently raised two factors as being particular important: (1) inspector experience and (2) information overload. Experience is essential in developing both specific and general device knowledge, but at the same time, the experiences that each inspector has can vary greatly, leading to a lack of consistency in inspector performance. This is exacerbated by the limited opportunities for inspectors to share knowledge 
and experiences between them. Inspectors also face a very large information barrier that expert inspectors manage to largely overcome, but that may be overwhelming for novice inspectors.

'Job Smarts and Automaticity' is another type of knowledge separate from specific device knowledge and 'common sense' critical thinking that plays an extremely important role in the performance of expert inspectors. Inspectors make use of strategies and heuristics in all aspects of the inspection task, and these make the inspection more efficient and more effective. The inspectors' ability to predict into the 'Past and Future', along with their ability to 'Improvise and Self-Monitor', plays an important role in an inspector's critical thinking about elevator and amusement devices, by allowing them to ask and answer questions that they ask to themselves and to others about these devices.

This initial analysis of the Knowledge Audit interview data highlighted several important types of knowledge that inspectors employ when performing inspections, along with how that knowledge is employed and barriers to its development.

\subsection{Taxonomies of inspector knowledge}

This following section describes the taxonomies that resulted from the iterative process of reanalyzing the Knowledge Audit interviews to create coding schemes that represent the variety of knowledge elicited in these interviews.

In the initial analysis of the interview data, many goals, strategies, and heuristics that inspectors employ during inspection were elicited, but in order to organize and present these in relation to how the inspection task is performed, a taxonomy of expert inspector knowledge that relates inspector knowledge directly to the inspection task is required.

As the initial analysis of the Knowledge Audit interviews was performed, a commonality was 
observed between the themes that were uncovered and the strategic/procedural/declarative knowledge model, as is illustrated in Table 2.

Table 2. Relationship between initial analysis themes and knowledge model

\begin{tabular}{|l|l|c|c|c|}
\hline $\begin{array}{l}\text { Expert } \\
\text { Characteristics }\end{array}$ & Themes & Strategic & Procedural & Declarative \\
\hline Big picture & Specific device knowledge & & & $\mathrm{x}$ \\
\cline { 2 - 5 } & 'Common sense' critical thinking & $\mathrm{x}$ & & \\
\hline $\begin{array}{l}\text { Principled and } \\
\text { systematic approach }\end{array}$ & $\begin{array}{l}\text { Driven by critical thinking about } \\
\text { inspection and device }\end{array}$ & $\mathrm{x}$ & & \\
\hline $\begin{array}{l}\text { Noticing and } \\
\text { anomalies }\end{array}$ & Importance of experience & $\mathrm{x}$ & $\mathrm{x}$ & $\mathrm{x}$ \\
\cline { 2 - 5 } & Information overload & $\mathrm{x}$ & $\mathrm{x}$ & \\
\hline $\begin{array}{l}\text { Job smarts and } \\
\text { automaticity }\end{array}$ & $\begin{array}{l}\text { Use of heuristics and specific } \\
\text { strategies }\end{array}$ & $\mathrm{x}$ & & $\mathrm{x}$ \\
\hline Past and future & Risk assessment & $\mathrm{x}$ & & $\mathrm{x}$ \\
\hline $\begin{array}{l}\text { Improvising and } \\
\text { self-monitoring }\end{array}$ & Assessing goals of task & Learning & & $\mathrm{x}$ \\
\cline { 2 - 5 }
\end{tabular}

The benefit of applying the strategic/procedural/declarative model of knowledge in the creation of the taxonomy of expert elevator and amusement device inspector knowledge lies in the fact that this model of knowledge more closely represents how expert inspector knowledge is applied in the real world, with strategic knowledge representing the inspectors' ability to think critically about the device and their inspection, procedural knowledge representing inspectors' 'job smarts' and lower-level strategies that aid in making the inspection more effective and more efficient, and declarative knowledge representing factual knowledge concerning devices, users, accidents, codes, and health and safety information.

It is important to note that in addition to the codes used below, all knowledge was also originally categorized based on the type of device that the knowledge pertained to. 


\subsubsection{Strategic knowledge}

Strategic knowledge is knowledge that details the high-level goals of the inspection task and that gives it a cohesive structure (Gott, 1988). The coding scheme that was developed for knowledge identified as being strategic consists of two hierarchical layers, the first representing the highlevel strategic tasks that are involved in the inspection task, and the second representing the subtasks that are involved in accomplishing the higher-level tasks. The categories and descriptions of this coding scheme can be found in Table 3.

The researcher identified the strategic knowledge employed in the inspection of elevator and amusement devices to consist of ten categories, the first seven of which represent the high-level goals of these inspection tasks, which are as follows:

1) Schedule inspection

2) Prepare for inspection

3) Preliminary assessment

4) Inspect for safety hazards

5) Safety hazard assessment

6) Initial inspection tests

7) After inspection.

Though these first seven strategic categories are semi-structured according to how they are performed in the field, they do not completely represent task flow. For example, an inspector is not likely to perform a safety hazard assessment for each potential hazard identified during the inspection after having completed the entire inspection; instead, he is likely to perform some sort 
of safety hazard assessment immediately after identifying each hazard.

The following two categories-

8) Communication and

9) Learning,

-represent high-level goals of the inspectors that do not strictly fall within the general

inspection goals, but are essential to the performance of expert inspectors. The final-

10) General

— category consists of goals that are not explicitly part of the first nine goals, but rather consists

of goals that encompass the entirety of the inspection task.

Table 3. Taxonomy of strategic knowledge

\begin{tabular}{|c|c|c|}
\hline CATEGORY & SUB-CATEGORY & DESCRIPTION \\
\hline Schedule inspection & & Concerning the scheduling of the inspection \\
\hline \multirow[t]{2}{*}{$\begin{array}{l}\text { Prepare for } \\
\text { inspection }\end{array}$} & & Concerning activities that are performed prior to arrival at the Inspection site \\
\hline & $\begin{array}{l}\text { Review } \\
\text { documentation }\end{array}$ & $\begin{array}{l}\text { Activities related to the reading and reviewing of documentation concerning AD's that } \\
\text { are to be inspected }\end{array}$ \\
\hline \multirow[t]{3}{*}{$\begin{array}{l}\text { Preliminary } \\
\text { assessment }\end{array}$} & & Concerning the assessment of a location prior to commencing inspection \\
\hline & Identify users & $\begin{array}{l}\text { Activities related to the assessment of device location, along with the users making } \\
\text { use of, maintaining, and operating the device }\end{array}$ \\
\hline & Identify device & Activities related to assessing the characteristics of the device \\
\hline \multirow[t]{10}{*}{$\begin{array}{l}\text { Inspect for safety } \\
\text { hazards }\end{array}$} & & Concerning the inspection of the device for safety hazards \\
\hline & Safety & $\begin{array}{l}\text { Activities related to ensuring the safety of the inspector and the public while the } \\
\text { inspection is performed }\end{array}$ \\
\hline & User perspective & Activities related to the assessment of the device from the perspective of its users \\
\hline & User as resource & Activities related to the use of users as an information source \\
\hline & Operation & Activities related to the assessment of the device by observing its normal operation \\
\hline & Inspection procedure & Activities related to the actual performing of the inspection \\
\hline & Assess maintenance & Activities related to the assessment of the maintenance that the device receives \\
\hline & Investigate & $\begin{array}{l}\text { Activities related to the investigation into indications of safety hazards that have } \\
\text { been identified in earlier stage of the inspection }\end{array}$ \\
\hline & Inspect components & Activities related to the inspection of specific components throughout the inspection \\
\hline & Troubleshooting ${ }^{*}$ & $\begin{array}{l}\text { Activities related to the troubleshooting of problems with the device that have } \\
\text { occurred during the inspections }\end{array}$ \\
\hline
\end{tabular}




\begin{tabular}{|c|c|c|}
\hline $\begin{array}{l}\text { Safety hazard } \\
\text { assessment }\end{array}$ & & Concerning the evaluation of identified potential safety concerns \\
\hline & Evaluate component & $\begin{array}{l}\text { Activities related to the identification and assessment of components that have been } \\
\text { found to contain potential safety concerns }\end{array}$ \\
\hline & $\begin{array}{l}\text { Consider } \\
\text { maintenance }\end{array}$ & $\begin{array}{l}\text { Activities related to the consideration of the maintenance the device is receiving } \\
\text { during salety hazard assessment }\end{array}$ \\
\hline & $\begin{array}{l}\text { Identify potential } \\
\text { outcomes }\end{array}$ & $\begin{array}{l}\text { Activities related to the consideration of the potential outcomes that could result from } \\
\text { not addressing the identified potential safety concerns }\end{array}$ \\
\hline & Assess solutions & $\begin{array}{l}\text { Activities related to the assessment of the potential solutions to the identified } \\
\text { potential safety concerns }\end{array}$ \\
\hline & Identify purpose & Activities involved with the identification of the purpose of initial inspection tests \\
\hline & Assess design & Activities involved with assessing the proposed design of the initial inspection tests \\
\hline & Assess efficiency & Activities involved with assessing the efficiency of the initial inspection tests \\
\hline & Redesign & Activities involved with assessing the redesigning of the initial inspection tests \\
\hline & Ensure validity & Activities involved with the observation and acceptance of the initial inspection tests \\
\hline After-inspection & & Concerning activities to be performed after the inspection has been performed \\
\hline & Communication & Activities involved with communication of inspection results to relevant parties \\
\hline Learning & & Concerning the learning of the inspector \\
\hline & Knowledge-building & Activities involved in growing inspector knowedge \\
\hline & Communication & Activities involved in communication that leads to increasing inspector knowledge \\
\hline General & & $\begin{array}{l}\text { Concerning high-level general strategies employed when performing the } \\
\text { inspection task }\end{array}$ \\
\hline
\end{tabular}

\subsubsection{Procedural knowledge}

Procedural knowledge encompasses the different strategies and heuristics that inspectors use to achieve specific tasks during inspections. Much procedural knowledge is made up of task

procedures that have been automated by the inspector. By automating certain elements of the inspection, mental resources are opened up for other tasks, such as the critical assessment of the device. 
The researcher identified procedural knowledge as not displaying any internal organizational structure because the specific heuristics and strategies that inspectors use are situationally and environmentally dependent. Inspectors will only use specific strategies at certain times during the inspection and on certain components. This is why the taxonomy of procedural knowledge does not have its own unique structure and instead consists of a combination of the strategic and declarative knowledge structures.

The taxonomy developed for the knowledge identified as procedural knowledge consists of four layers, the first two of which are identical to the two-layered strategic knowledge coding scheme. The third layer is an optional layer that allows the procedural knowledge to be labeled by lowerlevel strategic knowledge if a further layer of description is required. In addition to the first three hierarchical layers, a fourth optional layer was also added to relate the procedural knowledge to specific device components or locations.

\subsubsection{Declarative knowledge}

The taxonomy developed for knowledge identified as being declarative consists of a variable number of layers depending on the class of the knowledge. Five classes were identified by the researcher as representing the entirety of declarative knowledge. These classes were:

1. Device knowledge - knowledge concerning the components and functions of specific devices

2. Safety knowledge - knowledge concerning safety during the inspection task

3. User knowledge - knowledge concerning the various users of the device

4. Meta knowledge - knowledge concerning the variables affecting the inspectors' learning, knowledge, and inspection performance

5. Code knowledge - knowledge of the elevator and amusement device codes.

Each of these classes has its own taxonomy. 
'Device knowledge' was identified by the researcher as having a four-layer hierarchical taxonomy. The first two layers describe knowledge in terms of its relationship to the device. The first of these consists of the high-level nature of that knowledge, consisting of:

1) Knowledge of specific components

2) Knowledge of particular characteristics of each device

3) Knowledge of particular functions of particular devices

4) Knowledge of the operation of particular devices

The second layer further specifies the relationship between the knowledge and the device, by relating the knowledge to specific components or functions of the device.

The third layer describes the form of that knowledge, whether it consists of information about a device, indications that a particular device or component device may have a deficiency, known problems of a particular device or component, known characteristics of particular manufacturers, etc.

The fourth and final layer allows for further specification of the third layer. For example, if a piece of knowledge is identified as being related to a specific manufacturer in the third layer, then the fourth layer allows for specification of that manufacturer. Or if a piece of knowledge is identified as being an indication of a potential defect in the third layer, the fourth layer allows for that defect to be given a name, such as 'rust' or 'cracks'.

The taxonomy for 'device knowledge' can be found in Table 4.

The taxonomy for 'safety' and 'user' declarative knowledge can be found in Table 5 and Table 6 , respectively.

Safety knowledge was identified by the researcher as consisting of four categories:

1) Hazards 
2) Meta

3) Health and safety

4) Safety procedures

'Hazards' consists of knowledge about specific hazards that each device represents, 'meta' consists of knowledge of an inspector's own opinions on safety, 'health and safety' is knowledge concerning specific health and safety rules and regulations, and 'safety procedures' consists of knowledge of procedures that can be used to improve to overall safety of the inspection task. 'Safety procedures' may also become procedural knowledge if performed frequently enough by the inspector.

User knowledge consists of knowledge about the various users of a device. These users consist not only of the general public who use the amusement or elevator device, but also mechanics, owners, and inspectors. Each type of user was found to be defined by several categories:

1) User behaviour

2) User characteristics

3) User location

4) Point-of-view (POV)

5) Accidents

6) Individual characteristics

7) Relationship.

The final two type of declarative knowledge are 'meta' knowledge, which has a simple twocategory classification taxonomy, consisting of 'knowledge and learning' of inspectors and the 'performance' of inspectors, each of which contain five sub-categories, and 'code' knowledge, which was not coded because it already contains a strict structure based on the code itself. The taxonomy for 'meta' knowledge can be found in Table 7. 
Table 4. Declarative device knowledge coding scheme

\begin{tabular}{|c|c|c|c|c|}
\hline CATEGORY & SUB-CATEGORY & SECTION & SUB-SECTION & DESCRIPTION \\
\hline Components & & & & $\begin{array}{l}\text { Concerning the entirety of components making up an ED or AD } \\
\text { device }\end{array}$ \\
\hline & General & & & Knowedge related to the device as a whole \\
\hline & $\begin{array}{l}\text { (specific } \\
\text { components) }\end{array}$ & & & Knowledge related to specific components of the device \\
\hline & & Information & & $\begin{array}{l}\text { Knowledge related to descriptive information regarding the device } \\
\text { its components }\end{array}$ \\
\hline & & Indication & & $\begin{array}{l}\text { Knowledge related to indications of a safety concern with the device } \\
\text { or its components }\end{array}$ \\
\hline & & & (specific indication) & \\
\hline & & Maintenance & & $\begin{array}{l}\text { Knowledge related to the maintenance of the device or its } \\
\text { components }\end{array}$ \\
\hline & & Problems & & $\begin{array}{l}\text { Knowledge related to specific problems with the device or its } \\
\text { components }\end{array}$ \\
\hline & & & (specific problem) & \\
\hline & & Manufacturers & & $\begin{array}{l}\text { Knowledge related to the devices and components of specific } \\
\text { manufacturers }\end{array}$ \\
\hline & & & $\begin{array}{l}\text { (specific } \\
\text { manufacturer) }\end{array}$ & \\
\hline & & Failure & & Knowledge related to the failure of the device or its components \\
\hline Characteristics & & & & Concerning characteristics of a device \\
\hline & Domain-specific & & & Knowledge related to the specific domain of the device \\
\hline & Location & & & Knowledge related to the location of a device \\
\hline & Age & & & Knowledge related to the age of a device \\
\hline & Operation & & & Knowledge related to the operation of a device \\
\hline & Usage & & & Knowledge related to the usage of a device \\
\hline Functions & & & & Concerning the functions of a device \\
\hline & (specific functions) & & & \\
\hline & & Information & & $\begin{array}{l}\text { Knowledge related to descriptive information regarding the functions } \\
\text { of a device }\end{array}$ \\
\hline & & Problems & & Knowledge related to known problems with the functions of a device \\
\hline Operation & & & & Concerning the regular operation of the device \\
\hline & General & & & Knowledge related to the operation of devices as a whole \\
\hline & $\begin{array}{l}\text { (specific } \\
\text { component) }\end{array}$ & & & \\
\hline & & Information & & $\begin{array}{l}\text { Knowledge related to descriptive information regarding the regulat } \\
\text { operation of the device }\end{array}$ \\
\hline & & Indication & & $\begin{array}{l}\text { Knowledge related to indications of safety concerns with the } \\
\text { operation of a device }\end{array}$ \\
\hline & & & (specific indication) & \\
\hline & & Problems & & Knowledge related to known problems with the operation of a denge \\
\hline
\end{tabular}


Table 5. Declarative safety knowledge coding scheme

\begin{tabular}{|c|c|c|c|}
\hline CATEGORY & SUB-CATEGORY & LOCATION & DESCRIPTION \\
\hline \multirow[t]{3}{*}{ Hazards } & & & Knowledge of specific safety hazards with a device \\
\hline & (specific hazards) & & \\
\hline & & (specific locations) & \\
\hline Meta & & & Knowledge of the inspector's own opinions on safety \\
\hline \multirow[t]{2}{*}{ Health and safety } & & & Knowledge of health and safety regulations \\
\hline & & (specific locations) & \\
\hline \multirow[t]{2}{*}{$\begin{array}{l}\text { Safety } \\
\text { procedures }\end{array}$} & & & $\begin{array}{l}\text { Knowledge of safety procedures that can be incorporated into } \\
\text { the inspection procedure }\end{array}$ \\
\hline & & (specific locations) & \\
\hline
\end{tabular}

Table 6. Declarative user knowledge coding scheme

\begin{tabular}{|c|c|c|c|}
\hline CATEGORY & SUB-CATEGORY & COMPONENT & DESCRIPTION \\
\hline \multicolumn{4}{|l|}{$\begin{array}{l}\text { (specific type of } \\
\text { user) }\end{array}$} \\
\hline & User behaviour & & Knowledge concerning the behaviour of s type of user \\
\hline & - & $\begin{array}{l}\text { (specific device } \\
\text { component) }\end{array}$ & \\
\hline & User characteristics & & Knowledge concerning the characteristics of a type of user \\
\hline & User locations & . & $\begin{array}{l}\text { Knowedge concerning the locations in which a certain } \\
\text { type of user could be found }\end{array}$ \\
\hline & User POV & & Knowledge about the point-of-view of a certain type of user \\
\hline & Accident & & $\begin{array}{l}\text { Knowledge about accidents that have occurred involving a } \\
\text { certain type of user }\end{array}$ \\
\hline & $\begin{array}{l}\text { Individual } \\
\text { characteristics }\end{array}$ & & $\begin{array}{l}\text { Knowledge concerning characteristics of specific users (as } \\
\text { opposed to user types) }\end{array}$ \\
\hline & Relationship & & $\begin{array}{l}\text { Knowledge about maintaining a positive and functional } \\
\text { relationship with a certain type of user }\end{array}$ \\
\hline
\end{tabular}


Table 7. Declarative meta knowledge coding scheme

\begin{tabular}{|c|c|c|}
\hline CATEGORY & SUB-CATEGORY & DESCRIPTION \\
\hline \multirow[t]{6}{*}{$\begin{array}{l}\text { Inspector knowiedge and } \\
\text { learning }\end{array}$} & & Concerning the knowledge and learning of inspectors \\
\hline & Device knowledge & $\begin{array}{l}\text { Concerning the nature of inspector device knowledge in relation to } \\
\text { inspector knowiedge and learning }\end{array}$ \\
\hline & Sources of knowledge & $\begin{array}{l}\text { Concerning the sourced of knowledge available to inspectors in } \\
\text { relation to inspector knowledge and learning }\end{array}$ \\
\hline & Learning & $\begin{array}{l}\text { Concerning the nature of inspector learning in relation to inspector } \\
\text { knowedge and learning }\end{array}$ \\
\hline & Individual characteristics & $\begin{array}{l}\text { Concerning the nature of individual differences between inspectors } \\
\text { in relation to inspector knowledge and learning }\end{array}$ \\
\hline & Domain characteristics & $\begin{array}{l}\text { Concerning the nature of specific domains in relation to inspector } \\
\text { knowledge and learning }\end{array}$ \\
\hline \multirow[t]{6}{*}{ Inspector performance } & & Concerning the inspector performance \\
\hline & Knowledge & Concerning inspector knowledge \\
\hline & Limitations to performance & Concerning natural limitations to the performance of inspection \\
\hline & Individual characteristics & $\begin{array}{l}\text { Concerning the importance of individual differences between } \\
\text { inspectors in relation to inspector performance }\end{array}$ \\
\hline & Communication & $\begin{array}{l}\text { Concerning the importance of communication in relation to } \\
\text { inspector performance }\end{array}$ \\
\hline & Domain characteristics & $\begin{array}{l}\text { Concerning the importance of domain characteristics in relation to } \\
\text { inspector performance }\end{array}$ \\
\hline
\end{tabular}

\subsection{The difference between elevator device and amusement}

\section{device inspection}

During the task analysis phase of this research, two important characteristics of amusement device inspection were identified: (1) the limited amount of time spent performing amusement device inspection each year, and (2) the wide variety of amusement devices that must be inspected. These characteristics of amusement device inspection have a large impact on inspector learning because, as has already been discussed, experience plays a large role in the development of inspector knowledge. With the high amount of exposure and repetition that exists in the performance of elevator device inspection, inspectors have the opportunity to speak to a variety of mechanics, witness a variety of hazards, and to improve upon the procedures that they use 
during the inspection. In amusement device inspection, inspectors do not often have this opportunity-
"The thing with amusement rides in Canada it's about volume. The more you do, the more you find. The amusement ride season's only a very short. And what happens is you've got to be very careful, because it's not a year after that you do that stuff again. So a lot of information, you forget, or you don't remember, or it takes a little while for you to... So when you're talking about expertise, When last did you do it? You ask me now what happen and I remember those four relays, but you ask me in December, it'll be a whole totally. I won't even remember."
Inspector: "Yeah very few devices. That's one of the problems with amusement devices. That too, it's seasonal, you're not seeing it through the year. So then you don't see it again."
Interviewer: "So you have a lot of time to forget."
Inspector: "Yeah, you forget about it"
"I'm not an expert on amusement rides. Because you only do them for a couple of months a year and then you don't see them after that."

In spite of this, inspectors still state that experience with individual devices is of key importance to successful amusement device inspection performance-

Interviewer: "[...] So there's some difference between, as you get more experience, more things probably start popping out at you."

Inspector: "Oh, drastically."

Interviewer: "So why do you think that is? And what are some of the contributing factors?"

Inspector: "It's just experience. Just strictly experience. For certain rides, you basically know what the problems are. Just because you know about the ride, and in previous years, you've found that same problem. Sp you can remember, 'I remember that ride from two years ago, and I saw something,' and you'll look again and you'll find it."

Interviewer: "And do you think that's the main driving factor?"

Inspector: "Oh yeah."

Interviewer: "Just the experience of having seen--"

Inspector: "That's all it is."

"With amusement rides, I find that the more time I spend with them, the more thorough the inspection becomes. So I know I also need to look at this, you learn more information about the ride, and you pay specific attention to certain pieces, which may be a timesaving but then I find that the inspection only gets more and more involved and more thorough. Where if you don't really know the ride that well, the inspection tends to be more a visual inspection and more on the surface, you don't really dig deep." 
Experience with specific devices plays an important role in the inspection of these devices, but inspectors also use other techniques that aid them in their inspections. One of the primary aids to an inspector preparing for amusement device inspection are the device manuals and other documentation. Unlike with elevator devices, where inspectors are not usually aware of the details of the device that they will be inspecting until they arrive on-site, with amusement devices, inspectors know which devices they are scheduled to inspect. This allows inspectors to prepare for the inspection by reviewing the appropriate documentation-

"I have to step back and slow down for a moment. I have to start training my mind again. Okay, this is an amusement ride, this is what I did last year, this is what I know, because I have all the manuals and documents if I need a refresher. If I'm not sure, I'll spend a moment and flip through the manuals. "Okay, this is what I should look at a little bit closer." We have all those documents. Each inspector, We have a full-fledged document of that ride. The manufacturer, how it was made. And the manufacturer has a certain standard they want it inspected every year. So we use that as our guide too. So we're not totally lost, but you have to step back for a moment and say, "Okay, I might have forgot something, I have to go slower." [...]. I might have done that ride six years straight, that same ride, every year I'm going to go back, I'm going to look at it for a moment, and I'm going to maybe spend a moment just to flip through the pages to familiarize yourself with some of the problems that maybe I'm going to have to look in to."

Inspector: Preparation is purely looking at specifications of the bulletins, what it's supposed to do, what speed it's supposed to rotate and all that stuff.

Interviewer: And that's from the ride manual?

Inspector: Yeah, the ride manual itself.

Inspectors generally use this review of the documentation to identify important operational specifications (speeds, rider heights, etc.), to identify the main structural components and how forces act on those components, to identify the components with bulletins or NDT tests addressing them, etc. Although helpful, this is a time-consuming process, and if not performed prior to the actual inspection, an inspector will likely not have a large amount of time to review all of the documentation- 
"And you're there and the guy's standing there and he wants to get the inspection done,. he's got to get it done, well I flip through this manual and the guy's standing there breathing over your shoulder, and you're kind of flipping through this four-inch manual... You really can't look through that four-inch manual. You haven't got an hour to sit there and just look at that manual, you've got to make sure he's generally got what he needs, he's got to have operating manuals and maintenance manuals, you've got to have something there for it, but lot of the times you don't have time to go through the specifics."

In addition to the ride documentation, inspectors also have access to ride-specific checklists for a selection of amusement devices. Checklists serve as a memory aid and to highlight some of the most important inspection points on each device.

Another resource that inspectors employ during amusement device inspection is communication with those more familiar with the device-

During my investigation, a big part of it is talking to the operators, the people who are there most part of the day. And you talk about it and they'll say, "This ride is noisy. It's not like it used to be. When we got it was quiet. [...] You ask general questions. Has anything changed? Have you observed anything? Is it loose? Are you hearing any noise? Is anything wobbly? Are you having trouble operating this ride?"

Interviewer: "And why is it that you caught that and you think others didn't catch it?" Inspector: "I think that it could be the fact that it was a pretty unique device, the manufacturer is not around anymore. You don't see it anywhere else, and you just don't know how it's supposed to work. And I think sometimes it's that interaction with the operators and asking questions and so on [...]"

Because the operators and regular mechanics of a device can prove to be a rich source of information about that device, fostering a positive and reciprocal relationship with them can also be a very important tool in the effective performance of amusement device inspection. One inspector in particular felt strongly about the importance of fostering a positive relationship with amusement device operators-

"Yeah, you don't want to have a combative and you don't want to make people feel like you're testing them either. [...] I find if you are nice, just remember carnies are probably, you know what I mean, they haven't been treated well in most times. And if you show them respect, they give you their heart out. They tell you about the ride or what it does, or 
how to fix it. So it's about having that relationship. Remember this guy's there 12 hours a day, 7 days a week on this ride. He knows everything. Every single sound. If he finds that you're trying to trip him up, he'll shut his mouth and as an inspector, you'll never know anything. If you let him know he's doing something - because they do very good work. They work with children, and the safety of people, and people's lives. They got to make sure they're buckled in, they got to make sure they're safe, they're alert, the stopping, so they do very good work. A lot of people think they get hollered and screamed at by the public all day long because they haven't done something, but if you let them know that what they're doing is valuable, you feel appreciated. They will tell you everything you want to know. It's just a matter of giving people what they're due, that's all."

The consideration of the point of view of people who inspectors interact with on a day-to-day basis was, in fact, a factor that arose when discussing both elevator and amusement device inspection, which is why it was specifically made a sub-category of the declarative user knowledge coding scheme.

A third strategy that inspectors use when conducting amusement device inspection is observing the operation of the device. Ideally, this would be performed while the device is open to the public, as that allows inspectors to gather more information about the device than they could otherwise, but even if not opened to the public, observing the operation of a device can provide the inspector with a variety of information, such as the critical weight-bearing components and the components being exposed to the largest forces-

"Watch the ride. Every time. Have them run it for a moment. Just see what it does. Does it flip upside down, does it go this way or whatever? So you can start analyzing, 'Okay, the stress is going to be on that arm."'

-the forces that the riders will be exerted to-

"[...] you will know what the people's situation on that ride. If the people will be pushing down into the chair or will be hanging on some kind of thing. Or they are rotating, or when the rotation is happening, they're shaking, or they'll just... then you will have a general idea of people need what kinds of protection and what kind of protection is more important."

-the vibration along the footing- 
"And you look at the ground and you see the footing shaking. And you see a lot of that, and that's something that you start to worry a lot. Huge. You don't see that on the fixed rides as much, you see that on the rides they put together on the weekend."

- the relative movement of the different components of the device-

Watching a ride and seeing how much one of the cars swings compared to the other ones and you say, "I'll bet you the shock absorbers on that ride need to be replaced." That's why the thing swings so much.

- and if it is possible to observe the device while it is open to the public, other indications of the performance of the state of the device become available to observe, such as the behaviour of the operator-

"[...] and you see that every time the ride stops, the attendant actually walks over to one of the cars and holds it for people to get off. How come he's walking over to that same tub every time? They have to hold it. I bet you the brake isn't working under that thing."

-or rider behaviour-

"I will need to know a general idea of how the ride's running and how people are on it. Then you will think about what's the risky parts."

Inspectors also use a variety of other techniques, both strategic and procedural, during amusement device inspection, from higher level strategic strategies, such as assessing the maintenance staff by assessing their knowledge of their devices, to lower-level procedural strategies, such as identifying the components on traveling amusement devices that are constantly being taken apart and put together, or asking themselves "What goes in there?" for every hole they encounter during the inspection.

Much like with elevator device inspection, inspectors use a variety of techniques to overcome the difficulties associated with the retention of declarative knowledge. Although with amusement devices, this difficulty is exacerbated by the limited inspection season and the wide variety of 
devices. For this reason, the strategic and procedural knowledge involved in the inspection of amusement devices likely plays an even stronger role than they do in the inspection of elevator devices. 


\section{Chapter 5. Discussion}

\subsection{The inspection task}

The initial phase of this research consisted of a task analysis of the periodic hydraulic elevator and amusement device inspection tasks. The task analysis diagrams describe the inspection task from an explicit knowledge perspective. They describe the primary components that must be inspected during hydraulic elevator and amusement device inspection, along with some of the primary indications used to assess the state of those components. Because the diagrams only contain explicit knowledge and not implicit or tacit knowledge, they only represent a portion of the full inspection task. The relationship between these task analysis diagrams and the cognitive task analysis that followed will be presented in the Discussion chapter of this thesis.

The task analysis of the periodic inspection of amusement devices was intended to be performed much in the same way as the task analysis for hydraulic elevators. However, as the data collection progressed, a number of important differences between the two types of inspection were identified, the two most important of these are: (1) the amount of time spent performing this type of inspection each year, and (2) the variety of devices that exist in each domain.

An inspector will spend the bulk of his work year inspecting elevating devices, which include elevators, escalators, dumbwaiters, freight platforms, and lifts for persons with physical disabilities. Of the total variety of devices inspected each week by the average inspector, a consistent percentage of these is made up of hydraulic devices. Amusement devices, on the other hand, have a short inspection season, where an inspector will spend a total of one or two weeks a year performing inspections. 
In addition to this limited exposure to amusement devices, inspectors will also see a large variety of devices in a season, and depending on each inspector's amusement device inspection schedule, they may only see a small selection of the total variety of rides each season. The combination of a short inspection season with a large variety of devices means that, unlike with elevators, an inspector will have difficulty in becoming familiar with any one ride through on-the-job experience alone.

Because of these two factors, it was impossible to create a single task analysis diagram capable of capturing the inspection task of all types of devices. It also was not possible to create task diagrams of any individual device. Instead, a general task analysis diagram was created that captured high-level activities involved with all amusement device inspections, excluding bounces and water slides.

\subsection{Strategic, procedural, and declarative knowledge}

As already described in the Introduction chapter of this thesis, Woodcock $(2007 ; 2009)$ presented a model that details the tasks that amusement device inspectors perform once a potential defect has been identified. While this model describes what inspectors do in order to classify a defect, it does not describe how inspectors perform these tasks. For example, the process of identifying potential defects in an amusement device is described as a 'holistic observation' in which inspectors form "impressions of the defect types that might be present, [search] both for observable defects and broad visual, auditory and kinaesthetic patterns [...], or certain structural or mechanical features that the inspector recognizes as prone to wear or failure" (Woodcock, 2009, p. 358). Although referenced to some degree, a detailed description of the goals, knowledge, and strategies that represent how inspectors think about and perform this task are not 
investigated in depth. The taxonomies created in this thesis describe the goals, knowledge, and strategies that inspectors use to accomplish many of the tasks presented in the model put forth by Woodcock $(2007,2009)$.

In an earlier study, Woodcock (2003) discussed a number of strategies and heuristics that inspectors use when performing the inspection task, such as the use of documentation, pattern recognition, heuristics, and different cognitive styles. The research performed in this thesis echoes many of the findings of Woodcock (2003), but then situates these in a larger taxonomy of inspector knowledge. By placing these characteristics of expert performance within this larger taxonomy, a better understanding of how and when these strategies and heuristics are used, along with the relationships that exist between them, can be developed.

The strategic/procedural/declarative model of knowledge was identified as being an effective framework for a taxonomy of inspector knowledge. If the knowledge gathered in the Knowledge Audit interviews was organized by expert characteristics, the expressiveness of the data would have been limited by not directly linking it to the inspection task, but instead linking it to theorybased characteristics of expert performance. This would have created a barrier of theory between the taxonomies of knowledge and the actual application of that knowledge by experts in the field, and would have splintered strategic, procedural, and declarative knowledge among the multiple theoretical expert characteristics categories. The strategic/procedural/declarative model of knowledge, on the other hand, represents how expert knowledge is actually applied in the real world. Although many important themes regarding the nature of the elevator and amusement device inspection task were identified in the analysis of the interview data, converting this information into a taxonomy of expert inspector performance required a reanalysis of the data around the strategic/procedural/declarative model of knowledge, rather than around the major 
themes of the Knowledge Audit interview.

Inspectors are reliant on strategic, procedural, and declarative knowledge to perform inspections safely, efficiently, and effectively. If the performance of inspections were based solely on declarative knowledge, it would likely not be a successful inspection. Similarly, if inspections consisted of a strung-together collection of procedural knowledge techniques, it would likely not be a successful inspection. For example, an inspection based solely on declarative knowledge could involve an inspector going line-by-line through the code and checking each element of that code against the state of the device. That is of course not possible because the inspection would take an extremely long amount of time, and it is not possible for inspectors to retain every element of every code, bulletin, and variety of device in their memory at all times. This use of multiple layers of knowledge and multiple ways of assessing a device provides a buffer that can help make up for the deficiencies of human memory, and it makes inspection something other than pure memorization of declarative knowledge or a purely automated set of procedural tasks that are linked together. This is why inspectors do not define their job primarily as 'ensuring that the device adheres to the code to which it is subject', but rather as 'ensuring that the device contains no safety hazards that may affect its users.'

\subsection{The perception of knowledge}

In the presentation of the results of the initial analysis, inspectors' frequent referencing of 'confidence' and 'common sense' was interpreted as an indication of an important aspect of the inspection task that was not being captured in the task analysis diagram. Though the first analysis of the interview transcripts provided some examples and indications of the existence of this strategic knowledge, the second analysis of the data allowed for a more structured and detailed 
view of it. The identification and representation of expert inspector strategic knowledge can benefit the training of novice inspectors in several ways. One of these is that it will help refocus the perception of knowledge and experience from being concerned primarily with declarative device knowledge to being about the entirety of inspector knowledge. One of the reasons why so much of a focus is placed on on-the-job training and experience is because knowledge is largely thought of by inspectors as being declarative knowledge; and, because the elevator and amusement devices domains have such a large body of declarative knowledge, capturing and representing all of it is not possible.

In spite of the fact that strategic knowledge makes up an essential part of expert inspector knowledge, when inspectors discuss the knowledge that falls within this category, they often refer to it in vague terms, such as 'confidence' and 'common sense'. Yet when they discuss their device knowledge, they will be much more likely to speak using specific examples and referring

to specific manufacturers or components. So, while declarative knowledge receives a lot of recognition as being an important aspect of inspector performance, procedural and strategic knowledge are less recognized and are described as, for example, 'common sense' or 'confidence', instead of being described as the knowledge that they actually are.

Speaking about strategic knowledge in abstract terms can only make the novice's job of understanding all aspects of the inspection task more difficult, and so an effort should be made to make the strategic knowledge involved in the inspection more evident, much in the same way that declarative device knowledge, as illustrated by the task analysis diagram, currently is. By defining and representing strategic knowledge, it can move from being an abstract concept important to inspector performance to being a specific set of strategies and knowledge. By expanding the accepted definition of knowledge from being largely declarative to consisting of 
strategic, declarative, and procedural knowledge, the possibilities of capturing and providing knowledge to novice inspectors are expanded. This move from the abstract to the creating and the sharing of an expanding taxonomy of inspector knowledge will provide novices with a framework around which they can organize their gathered knowledge, and as they collect knowledge, they will have an understanding of the relationship of each collected piece of knowledge to the greater structure of the entirety of their knowledge. Creating a taxonomy of knowledge that can grow as the understanding of the inspection task grows also opens the opportunity of the selective capturing of knowledge.

\subsection{Information overload}

In the discussion in the Results chapter of the nature of the information overload that inspectors face, it was mentioned that the amount of declarative knowledge that an inspector is expected to retain is so great that it takes years to begin to gain a level of comfort in performing inspections. Much declarative knowledge would, admittedly, be difficult to capture because "you can't know everything, this business is just... there's so much to learn, and there's so many different companies. [...] you might go fifteen years before you even see this particular problem or company or whatever." But while it might never be possible to standardize a large majority of the declarative device knowledge among inspectors, it may be possible to capture and standardize some of the procedural and strategic knowledge involved in the inspection task.

In addition, because the possession of knowledge is a very important aspect of the inspection task, to understand the nature of the information overload that inspectors face requires an understanding of the forms that that knowledge takes. Even if a large portion of the knowledge that an inspector collects over his years on the job will be difficult, if not impossible, to replace 
through the creation of a taxonomy of knowledge, if novices are provided a taxonomy, even if it is not completely populated, it will provide them with a framework around which they can organize the knowledge they have collected through experience.

\subsection{Consistency}

Throughout the interviews, it was observed that currently at the TSSA, learning occurs largely through experience. That this case-based learning plays an important role in inspector knowledge-building is evidenced by the fact that, throughout the Knowledge Audit interviews, inspectors would consistently make references to particular accidents or particular instances when describing their knowledge. This use of examples occurred regardless of whether inspectors were discussing declarative, procedural, or strategic knowledge. What and when inspectors learn depends on the variety of devices they inspect, the mechanics that they interact with, the mistakes they make, and chance. Because this type of learning makes up such a large proportion of how inspectors learn, it is not surprising that a lack of consistency has been observed between inspectors.

Although it would be unreasonable to expect to be able to capture and represent all of the knowledge that inspectors currently gain through this on-the-job learning, by understanding and creating knowledge taxonomies of expert inspector performance, a proportion of inspector knowledge can be taken out of the hands of on-the-job experience and chance and put into a more structured training program. There are several ways of moving forward with the knowledge structure established in this project, which are discussed in the Recommendations chapter of this thesis. 


\subsection{The importance of experience}

The process of becoming an inspector is one that takes place over many years, and the collection of knowledge that is contained within the entirety of the inspection workforce is at the very core of the TSSA. Currently, when an inspector leaves or retires, the majority of the knowledge that they have acquired over their tenure at the TSSA is lost because, as was discussed in the Results chapter of this thesis, the transfer of knowledge between inspectors at the TSSA is limited.

Even accepting that a portion of expert inspector knowledge cannot be captured, it is worthwhile modeling inspector knowledge to gain an understanding of which knowledge can and which knowledge cannot be captured, because capturing even a small amount of inspector knowledge would be preferable to the current state, in which the entirety of an inspector's knowledge is lost once they leave the TSSA.

\subsection{Limitations and future work}

One of the limitations of this project was that although the taxonomies of inspector knowledge that were developed do represent models of inspector knowledge and identify some of the major types of knowledge that experts have and employ, they do not necessarily represent the full relationships of all the elements within and between them. So although inspectors use strategic, procedural, and declarative knowledge in combination while performing inspections, how the relationships between these different types of knowledge function has not been represented.

A second potential limitation of this project was that the knowledge elicited was limited by the questions that were asked. Although the Knowledge Audit interview was designed to capture a number of main characteristics of expert performance, it does not represent all characteristics of expert performance, and so the knowledge elicited from the interviews may not be completely 
representative of all knowledge involved in the inspection tasks. Interviews were kept open by inviting and allowing inspectors to discuss other aspects of the inspection task that they felt were relevant to their performance as expert inspectors. Despite this, the interviews were ultimately guided by the Knowledge Audit interview questions, and it is acknowledged that these may have limited the scope of information collected.

Finally, this thesis project only aimed at creating and not populating taxonomies of expert inspector knowledge, and so opportunities to begin capturing and developing ways to represent this knowledge for inspectors should be explored. 


\section{Chapter 6. Conclusions and Recommendations}

This study established the existence of expert performance in the elevator and amusement device inspection domain by investigating the following characteristics of expert performance: big picture, principled and systematic approach, noticing, anomalies, job smarts, automaticity, past and future, opportunities and improvising, and self-monitoring. That expert performance exists in these domains means that literature pertinent to expertise can be considered in supporting inspection performance, and that this type of inspection is a legitimate domain for conducting further studies of expertise in general.

Secondly, the study confirmed that, like declarative knowledge, strategic and procedural knowledge can be captured and represented within a knowledge framework. Participants were readily able to generate examples and respond to the knowledge elicitation prompts, providing reassurance that interactive structured interviews can be a fruitful method of eliciting expert knowledge using a reasonable amount of resources, as long as a basic familiarity with the task domain and terminology has been acquired. Though while structured interviews proved to be effective, it may also be worthwhile to employ other forms of knowledge elicitation suitable to be integrated into inspectors' ongoing professional development.

This study derived a structure of inspector knowledge through the analysis of the knowledge elicited from a sample of expert inspectors. The knowledge elicited from individual participants overlapped with other participants to a notable degree, suggesting that it was being drawn from a common body of knowledge. At the same time, it is also likely that any knowledge elicitation process established at the TSSA would have to be ongoing because the body of inspector knowledge is not static. Inspectors reported continuous development of new technology leading 
to new knowledge of all three types. Thus, the knowledge taxonomy should be used as an organizational structure, but the process of populating the taxonomy will likely never be "completed".

Third, though the importance of all three of these types of knowledge to expert inspector performance was identified, only declarative knowledge is directly addressed during inspector training, leaving both procedural and strategic knowledge to be gained through on-the-job experience. This finding represents an opportunity for the improvement of the efficiency of inspector training, and collecting and representing strategic and procedural knowledge is the first step toward presenting this knowledge in a training setting. Also, while representing knowledge in a taxonomy may not alter the fact that some knowledge must be experientially acquired, the representation can help novices to understand and organize the knowledge that they gain through these experiences.

There are three recommendations that results from this thesis. First, it is recommended that the knowledge taxonomy be used as a common structure for documenting and discussing inspector knowledge. As this thesis has noted, every expert organizes her or his knowledge in some way, often unconsciously, and when knowledge is organized in this manner, it is less accessible for exchanging between inspectors. Conscious use of a knowledge structure makes implicit knowledge organization explicit and use of a common structure maximizes the ability of users to exchange information. This would be expected to have particular benefits for novice inspectors who may be exposed to information faster than they are able to derive a knowledge structure, and therefore may not be successful at retaining all new information acquired. Providing a common knowledge structure would relieve the metacognitive work of learning, since learners will be able to exploit the provided structure, and insert new knowledge into that structure. 
A common knowledge structure supports greater uniformity of knowledge content, as expert inspectors faced with a novel problem will know where to find relevant information that is known to their colleagues. Formalizing the knowledge structure will also enable expert peers to share and combine their knowledge, bridging different experiences using a common method of description.

Second, it is recommended that knowledge capture activities be initiated at the TSSA. Though this study has identified the variety of knowledge that inspectors employ, along with the structure of that knowledge, much of the knowledge that the taxonomy describes has not yet been collected. Collecting strategic and procedural knowledge and making it available to all inspectors can aid in improving inspector efficiency, effectiveness, and consistency. This is of particular importance in limiting the loss of knowledge caused by attrition due to retirement and career changes.

Third, representations for organizing this captured knowledge must be developed. Although these taxonomies represent the varieties of knowledge that inspectors employ, their current form may not represent the most effective means of presenting this knowledge to inspectors. One of the limitations of these taxonomies is that although they do identify the different categories within strategic, procedural, and declarative knowledge, they do not illustrate the relationships between them. So, although the strategies and knowledge that inspectors use have been identified, how and when they decide to use them has not been clarified. Further study is recommended to identify the conceptual relationships among the units of knowledge and their use, as this will likely lead to knowledge representations that will be more conducive to knowledge sharing. For these studies, concept maps are worth consideration, as that method focuses on the relationships among units of conceptual knowledge and represents it in an accessible notation. Like ongoing 
elicitation of knowledge, a concept map could be a "work in progress" that could dynamically grow and reflect emerging metacognitive awareness of knowledge as well as emerging technical developments.

By introducing the taxonomies of inspector knowledge into inspector training, by beginning knowledge capture activities, and by further developing the taxonomies of inspector knowledge through the creation and distribution of an ever-growing model of inspection performance, inspector training and inspector performance can be made more efficient, more effective, and more consistent. 


\title{
Appendix A: TSSA employee consent form
}

\author{
RE: Ryerson University Research Project - Task and Cognitive Task Analysis of Elevating \\ and Amusement Device Inspection
}

Our visit to your workplace is part of a research project known as THRILL to develop a task description and analysis of amusement ride inspection including the inspection that occurs during maintenance and operations. The research is being carried out by Ryerson professor Kathryn Woodcock, $\mathrm{PhD}$, PEng and graduate student Andrew Novak, BASc, funded by the Natural Sciences and Engineering Research Council (NSERC). Your employer, Technical Standards and Safety Authority ("TSSA"), has agreed to help with this research by allowing us to observe in the workplace. We plan to observe a variety of technical device inspections and interview inspectors. We will combine all of our observations. The analysis may be published and once a report is available, you will be able to receive a copy by contacting Dr. Woodcock by e-mail or visiting the project web page at the THRILL project website www.ryerson.ca/thrill

We plan to spend some time in your workplace with you, if you agree. Your manager has said that we may ask you to participate, but your participation is completely voluntary. Whether you decide to participate won't affect your future relations with Ryerson University, and TSSA has agreed that it will not affect your future relations with TSSA.

During our time with you, we would like to watch you and ask you questions about what you are doing. We are trying to make sure that we understand the type of work that has to be done, not evaluate your performance. These observations will not be used to rate or evaluate your performance.

We would also like to get some pictures that might show the working conditions, for example, what you can see from a given position, or the spaces you have to squeeze through to get at the parts. We don't want you to do additional tasks, just perform your normal work as much as possible. We don't want to disturb your concentration but we may not recognize tricky situations when they come up so please tell us when you need us to just be quiet or even to step away for a while, so that you can concentrate on a problem. We will use and/or wear any safety or protective clothing, devices or equipment as may be required at the workplace and we will obey your instructions regarding the workplace, including without limitation, not touching any equipment, devices or facilities at the workplace or leaving the workplace immediately if requested by you to do so.

Any research project can have risks as well as benefits. This project may give us valuable insights that might help us develop ways to help inspectors in this field as well as other areas involving mechanical devices. However it is possible that having us around watching might make you uncomfortable. If so, please let us know so that we might find a less uncomfortable way to observe. If you should change your mind about participating at any time after we start, just let us know and we will stop. 
We will not be recording your name other than on this consent form, which will be stored separately from all of the other records we make of our visit. We will be summarizing what we observe in the field, but we will not identify any individuals. If we take photographs, the purpose is to record the appearance, size, and shape of the workplace and the way the task is performed. We will automatically cover your face if it shows in a photograph. We may report descriptions of the work using specific examples, but we will not identify any individuals. In most cases, the examples that we give will be typical therefore they could have involved several other people who have been observed. If we report an unusual example, we will report it in a way that avoids revealing either you specifically or your workplace. If one of our research team witnesses an event that later becomes a subject of litigation, or is perceived to be a witness, the researcher will do everything legally possible to maintain confidentiality.

This research has been approved by the Ryerson University Research Ethics Board. If you have any concerns about this research, we encourage you to discuss it with your manager and us. You may also contact us by email at kathryn.woodcock@ryerson.ca. If you prefer, you may contact Ryerson University, School of Occupational and Public Health or the Research Ethics Board (c/o Office of Research Services, Ryerson University) at alex.karabanow@ryerson.com.

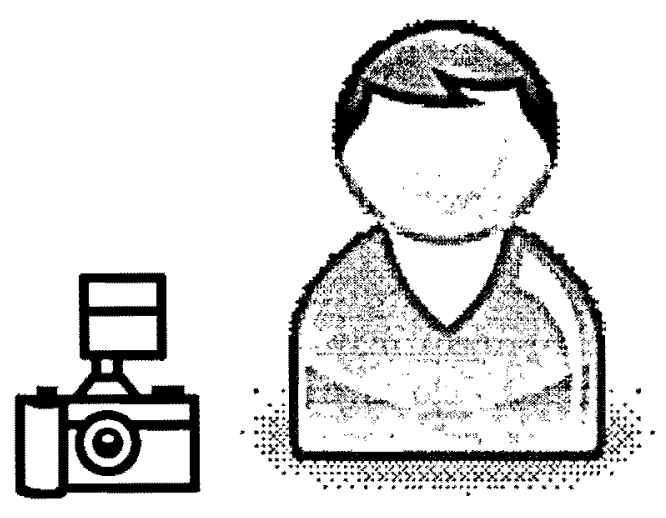

I do not want any part of my face or body to be visible in any photographs taken during my interview/shadowing.

Initials 
Appendix B: Task analysis of periodic hydraulic ED inspection 


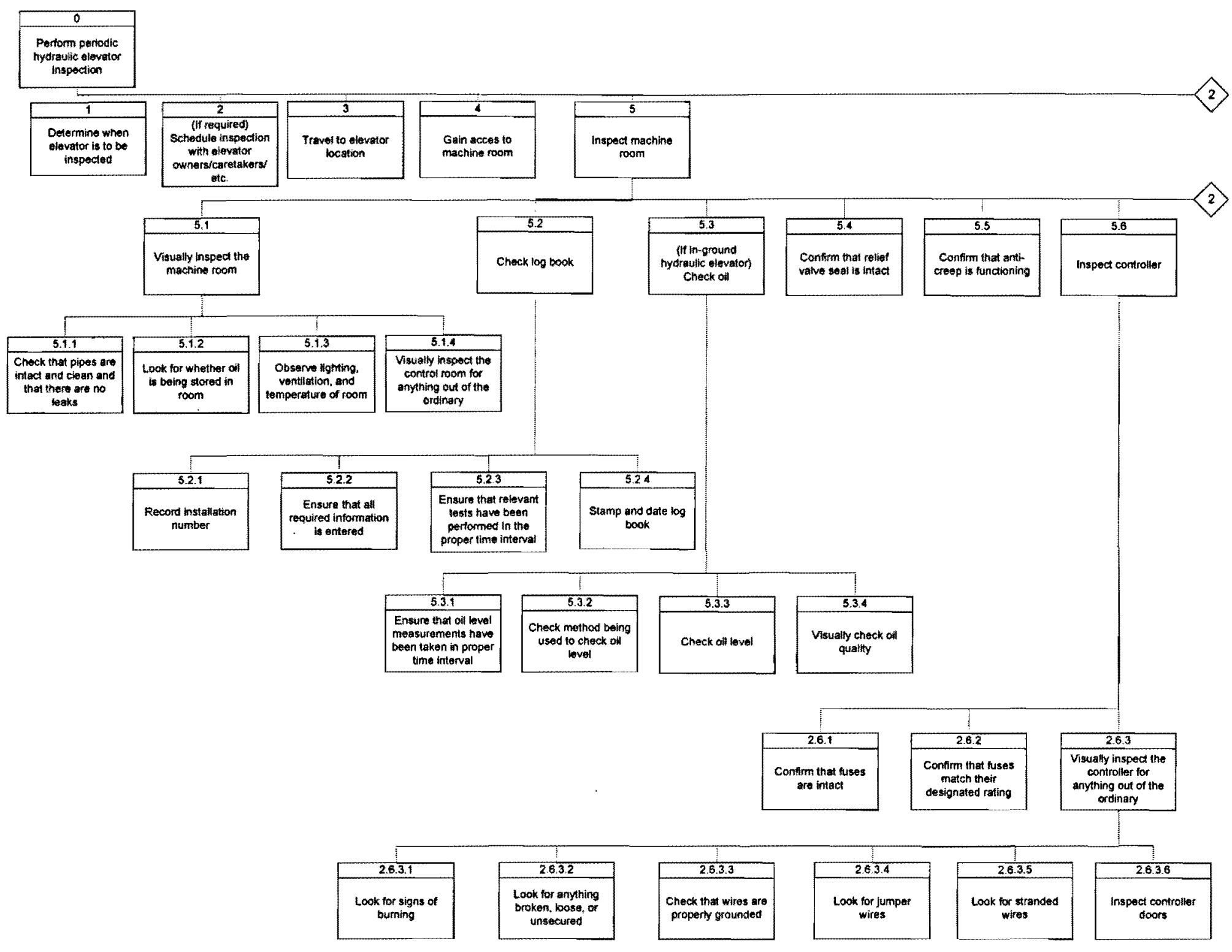




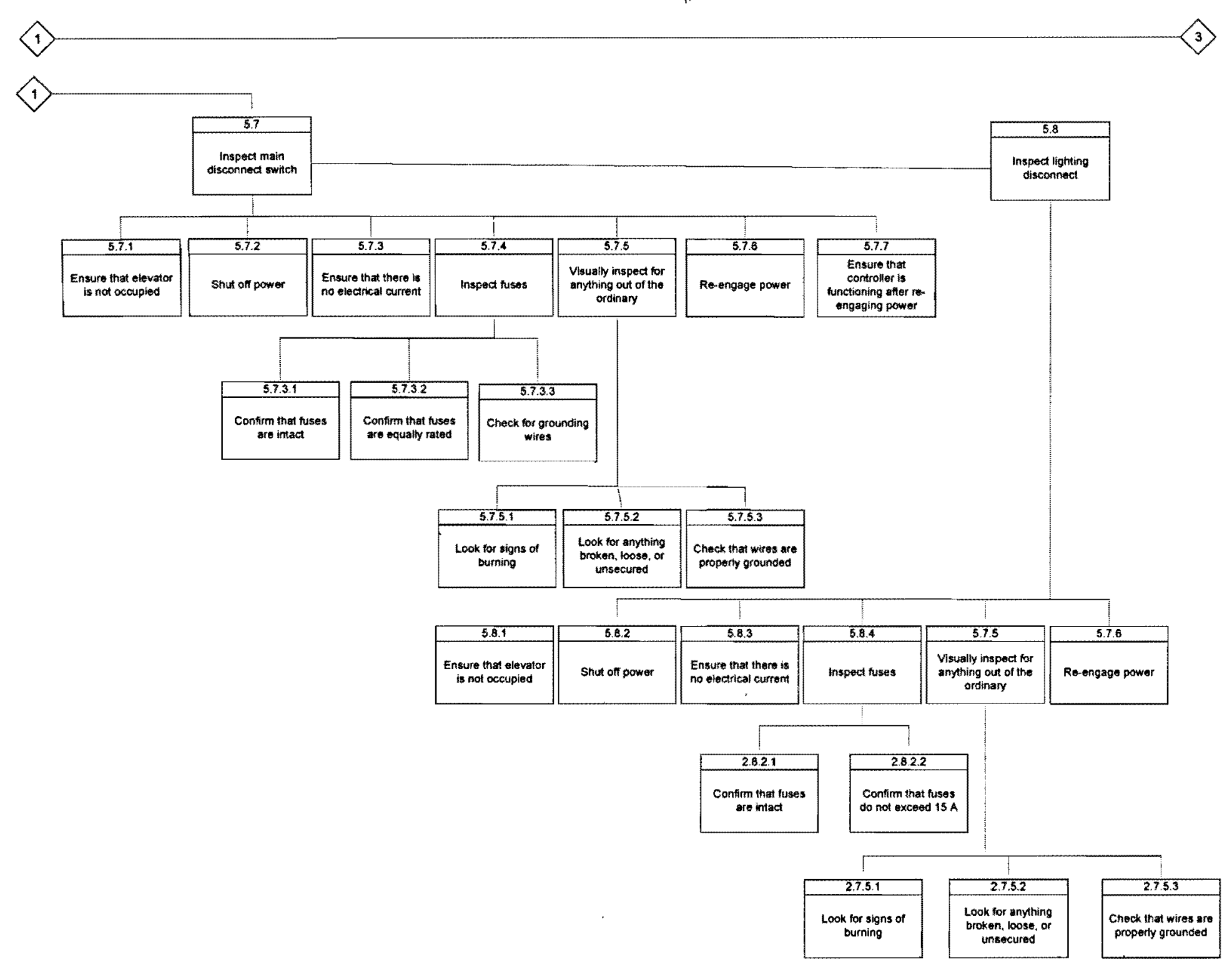




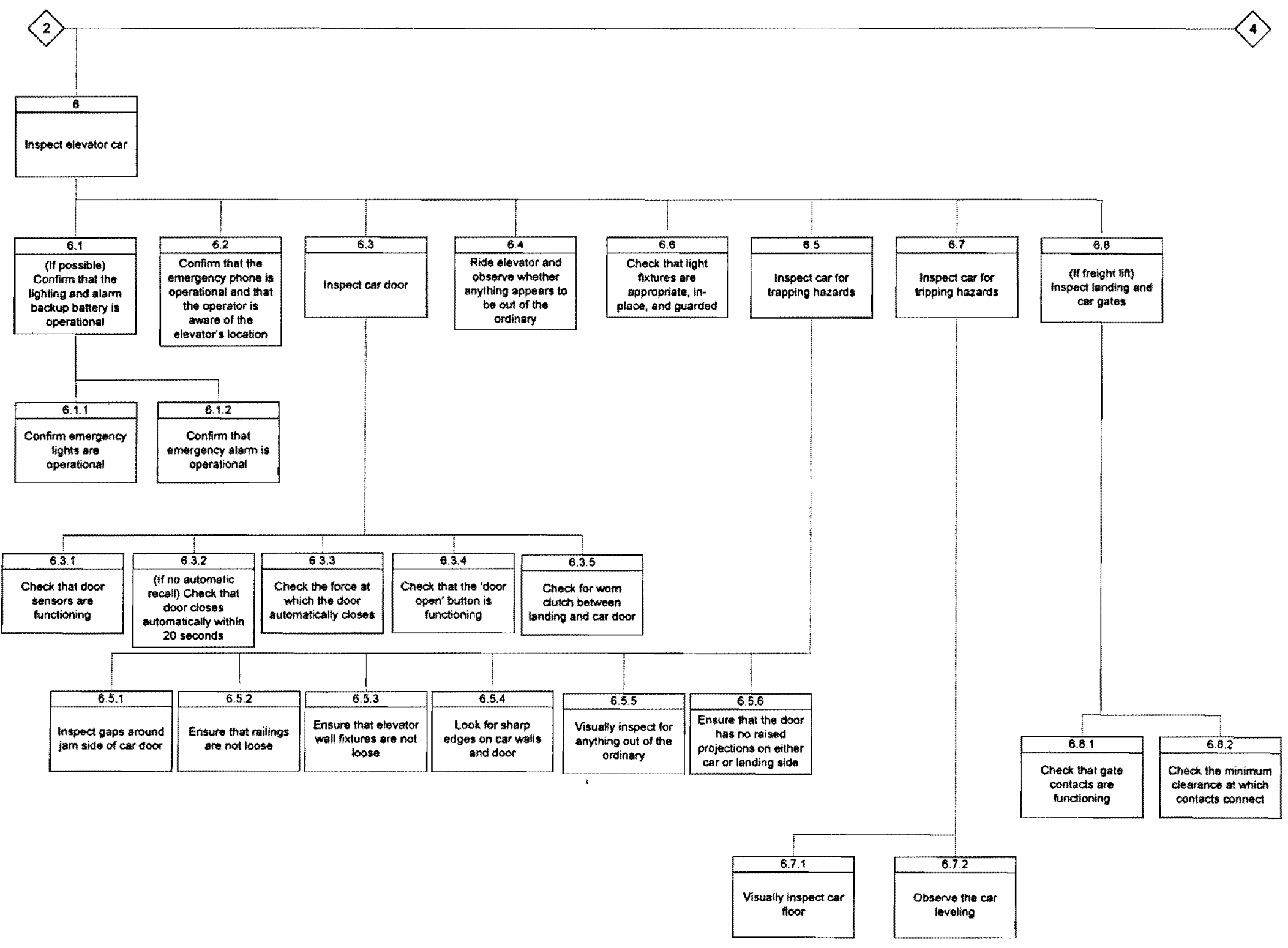




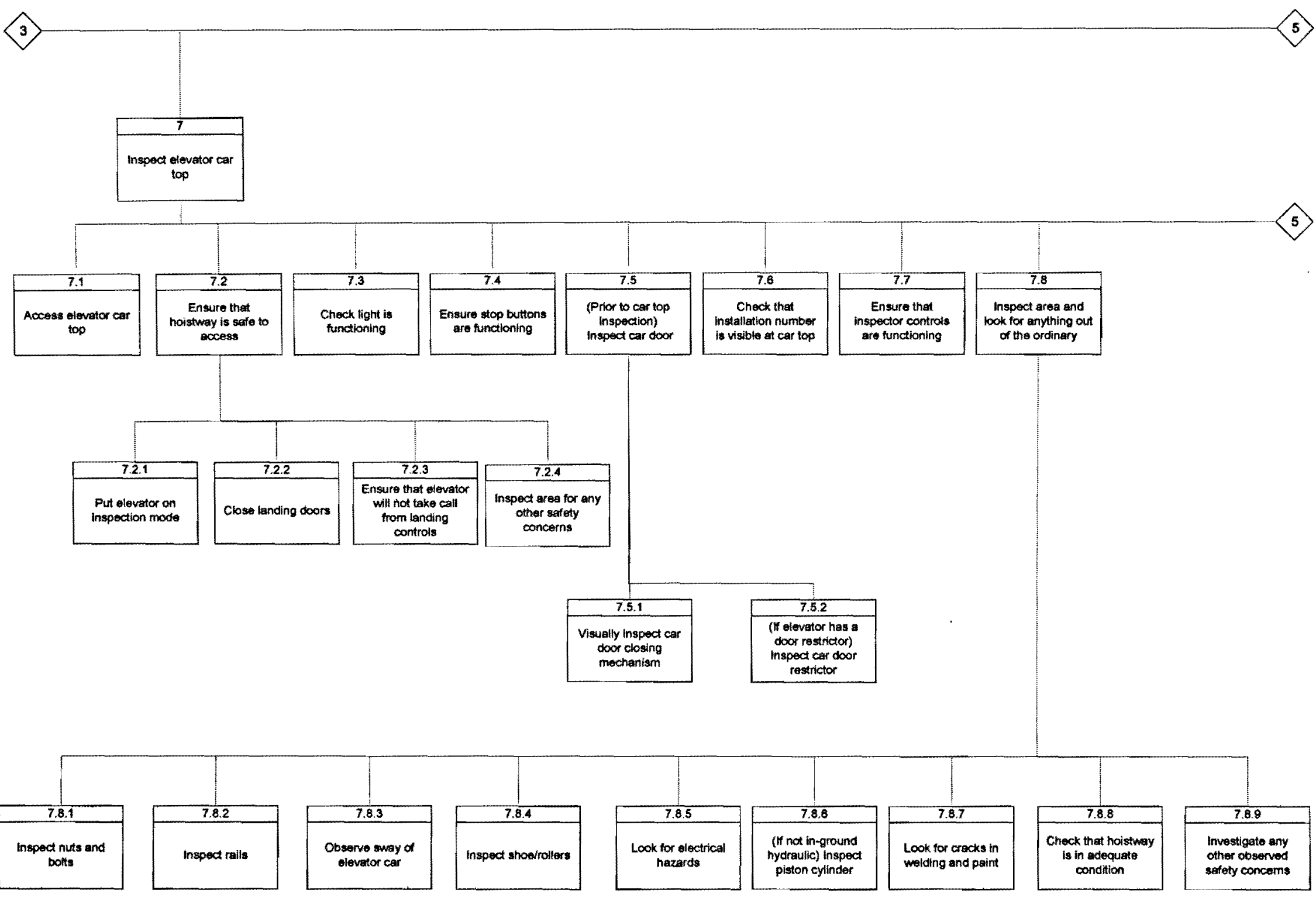




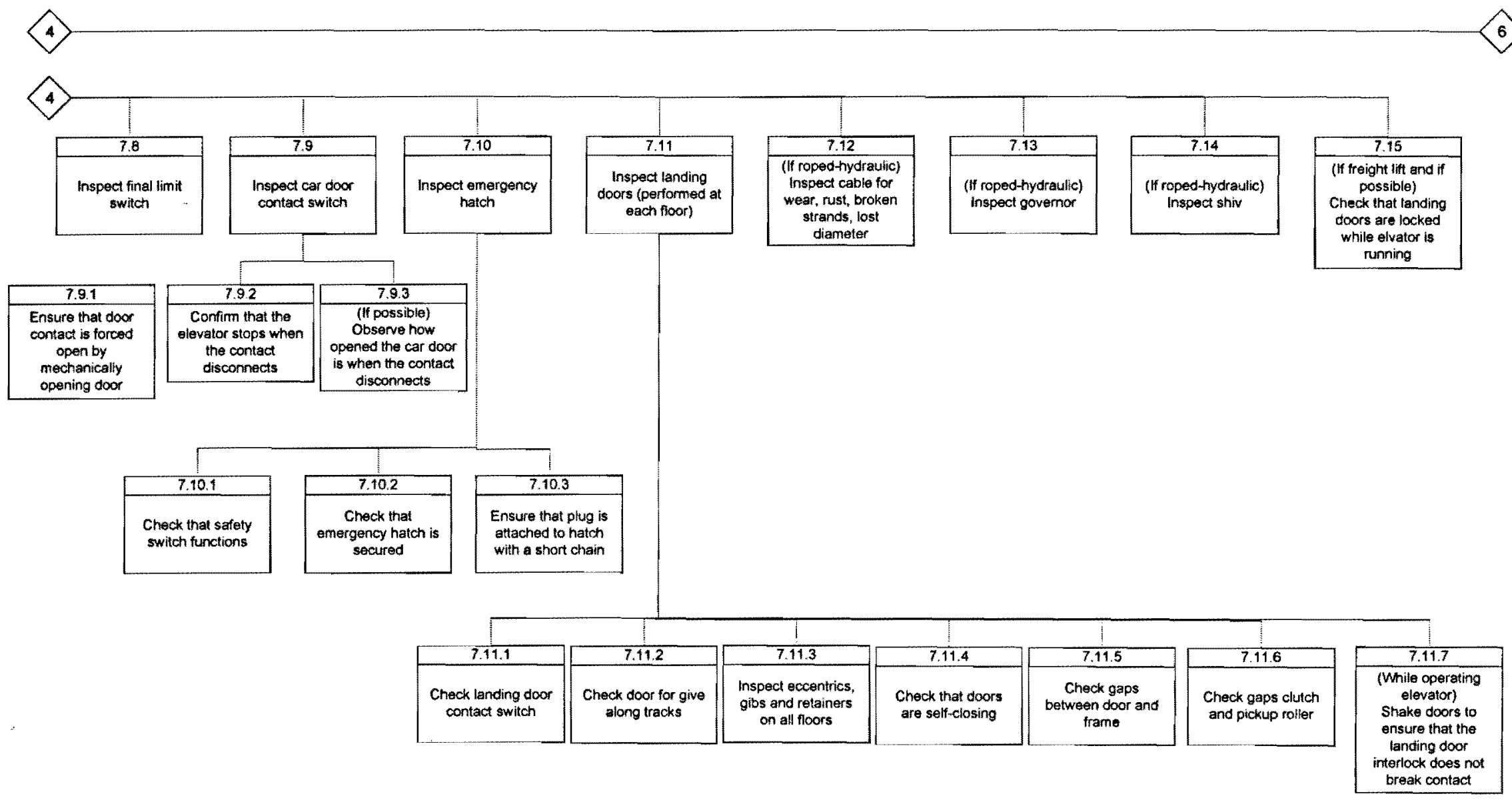




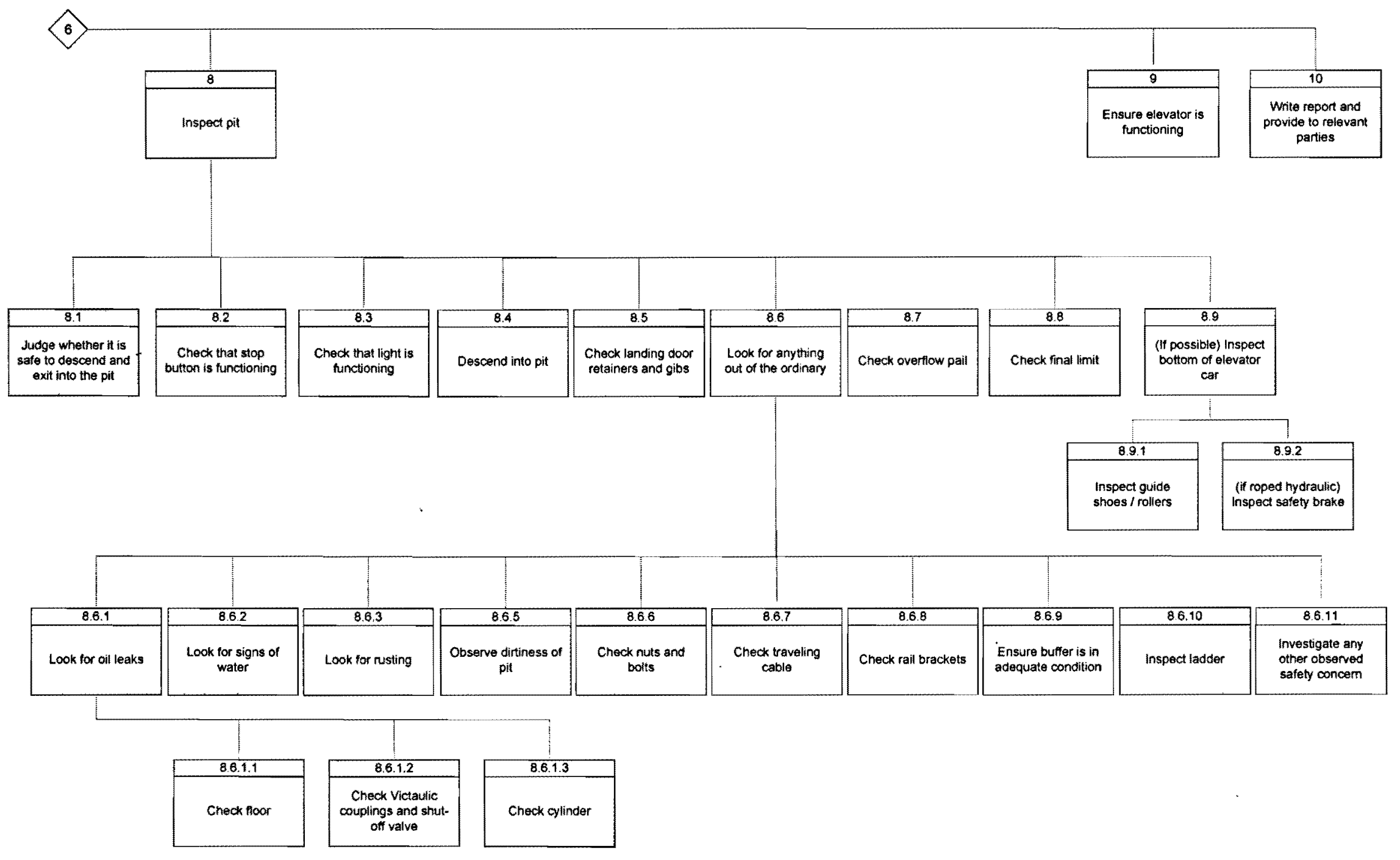


Appendix C: Task analysis of AD inspection 


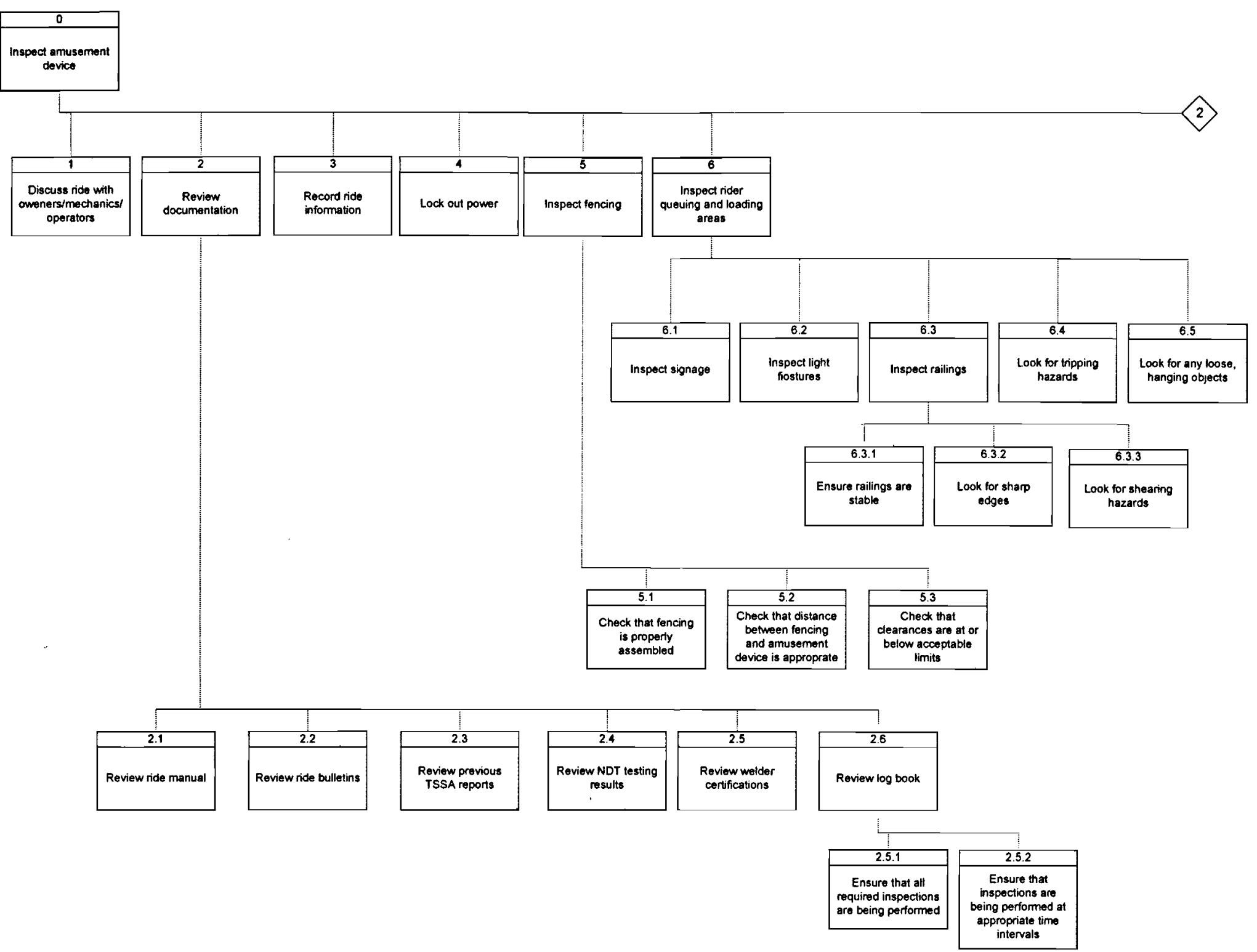




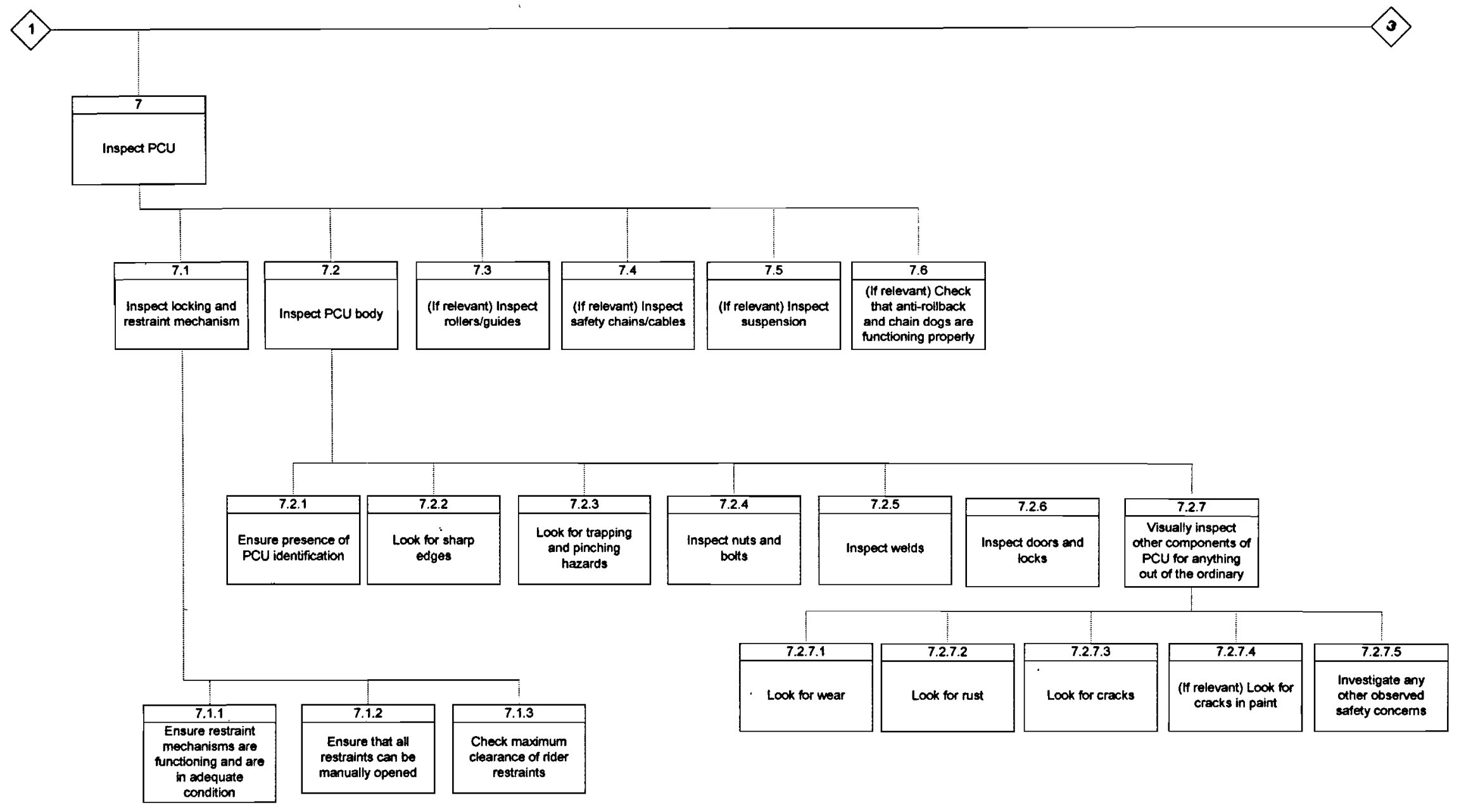




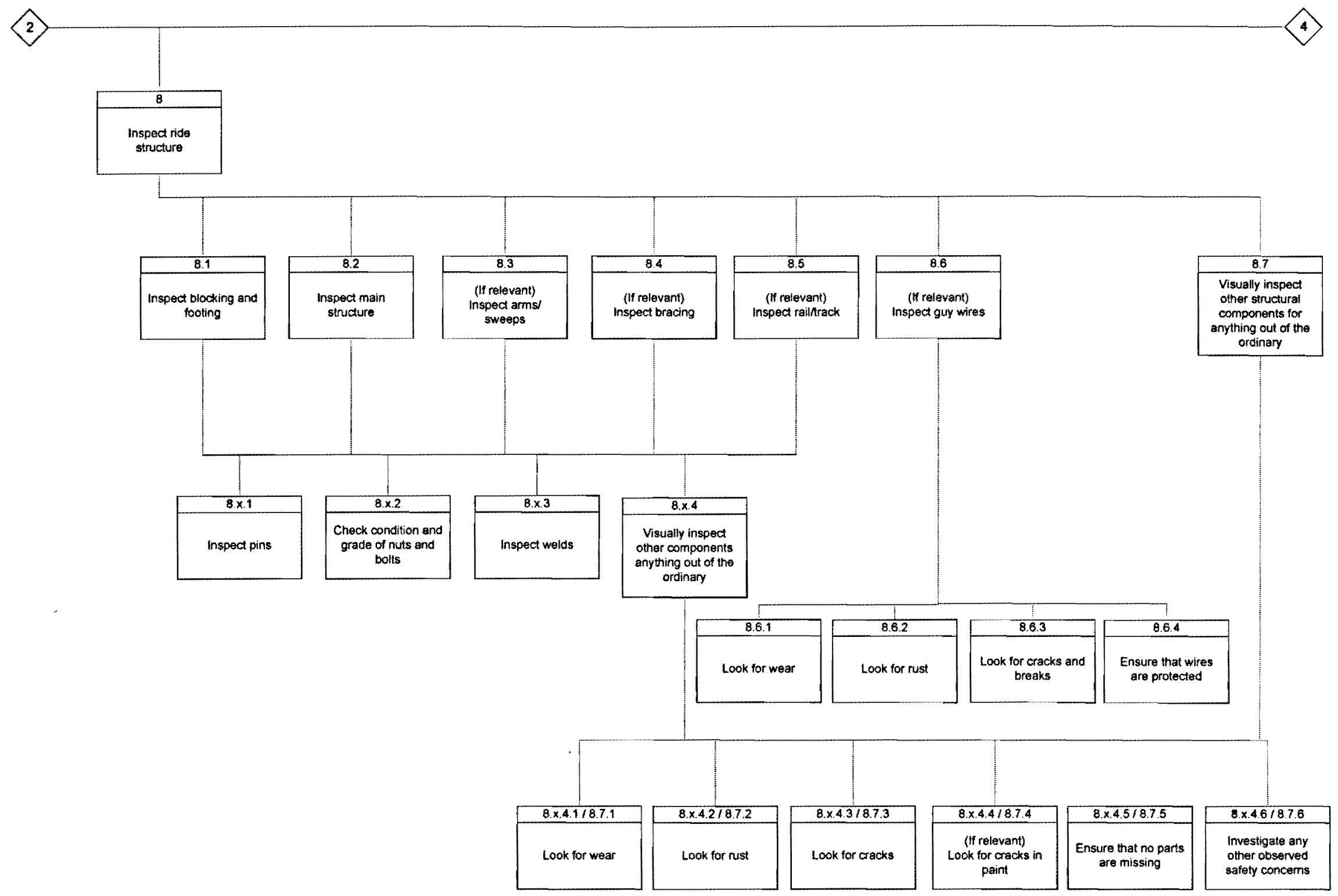




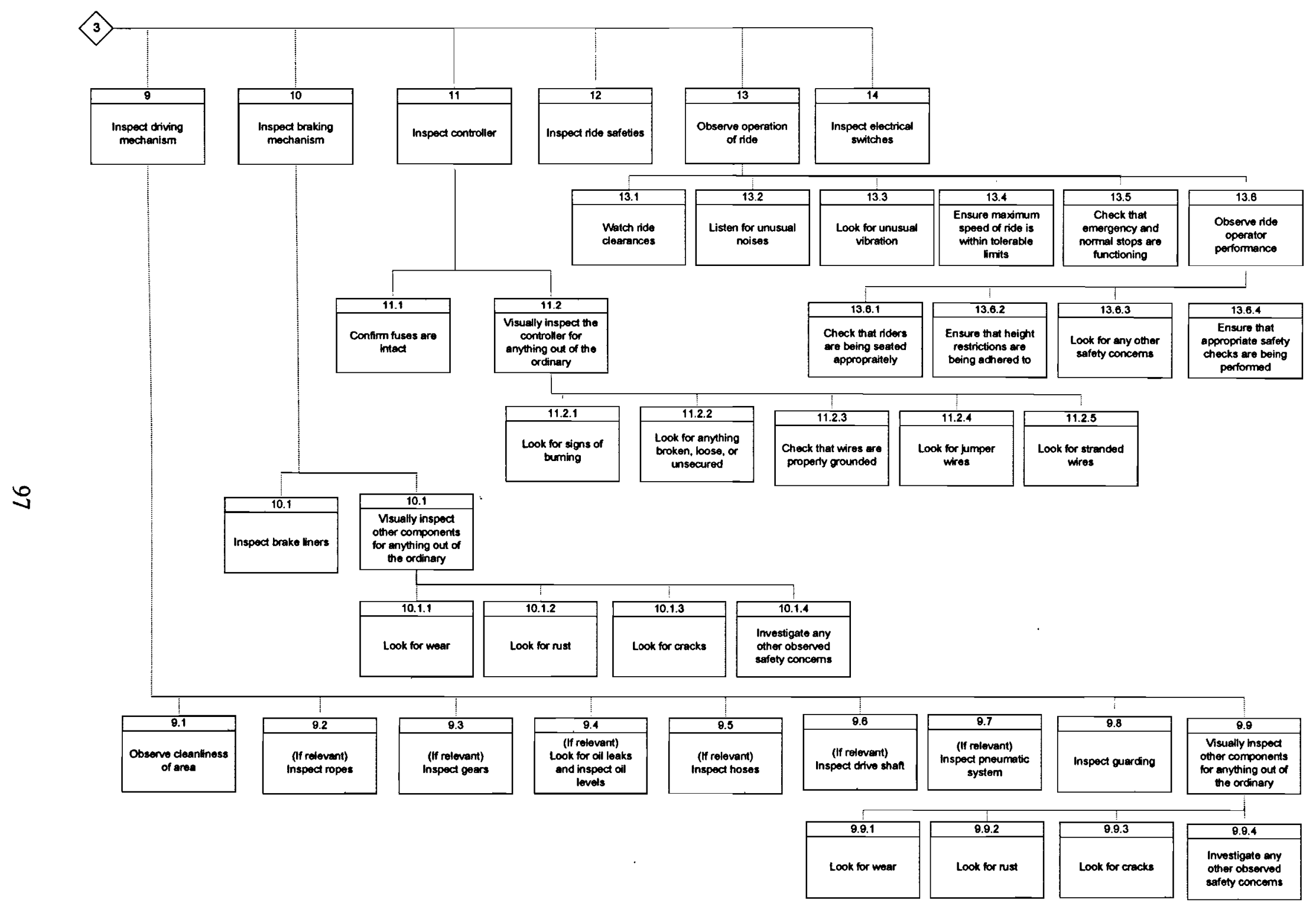




\section{References}

Allocco, M. (1997). Development \& application of the comprehensive safety analysis technique. Professional Safety. 42(12). 24-28.

Auld, M. C., Emery, J. C. H., Gordon, D. V., \& McClintock, D. (2001). The efficacy of construction site safety inspections. Journal of Labor Economics, 19(4), 900-921.

Ball, L.J., Evans, J.S.B.T., Dennis, I. and Ormerod, T.C. (1997). Problem-solving strategies and expertise in engineering design. Thinking and Reasoning, 3, 247-270.

Cellier, J. M., Eyrolle, H. \& Marinea, C. (1997). Expertise in dynamic environments. Ergonomics, 40, 28-50.

Chi, M. Two Approaches to the Study of Experts' Characteristics. (2006). In K. A. Ericsson, N. Charness, P. J. Feltovich, R. R. Hoffman (Eds.), The Cambridge handbook of expertise and expert performance (21-30). Cambridge University Press.

Chi, M. T. H., Glaser, R., \& Farr, M. J. (Eds.). (1988). The nature of expertise. Hillsdale, NJ: Erlbaum.

Chi, M.T.H., Glaser, R., \& Rees, E. (1982). Expertise in problem solving. In R.J. Sternberg (Ed.), Advances in the psychology of human intelligence (Vol. 1.) Hillsdale, NJ: Erlbaum.

Clark, R. E., \& Estes, F. (1996). Cognitive task analysis for training. International Journal of Educational Research, 25(5), 403-417.

Cooke, N. J. (1994). Varieties of knowledge elicitation techniques. International Journal of Human-Computer Studies, 41(6), 801-849.

Crandall, B., Klein, G. A. \& Hoffman, R. R. (2006). Working minds: A practitioner's guide to cognitive task analysis. MIT Press.

Farrington-Darby, T., \& Wilson, J. R. (2006). The nature of expertise: A review. Applied Ergonomics, 37(1), 17-32.

Feltovich, P. J., Pietula, M. J., \& Ericsson, K. A. Studies of expertise from psychological perspectives. (2006). In K. A. Ericsson, N. Charness, P. J. Feltovich, R. R. Hoffman (Eds.), The Cambridge handbook of expertise and expert performance (41-67). Cambridge University Press.

Frappaolo, C. (2008). Implicit Knowledge. Knowledge Management Research \& Practice, 6(1), 23-25.

Frederiksen J.R., White B.Y. (1993). The avionics job-family tutor: An approach to developing generic cognitive skills within a job-situated context. In P. Brna, S. Ohlsson, \& H. Pain (Eds.), Proceedings of the World Conference on Artificial Intelligence in Education, 513520. Charlottesville, VA: Association for the Advancement of Computing in Education.

Gitomer, D. H. (1988). Individual differences in technical troubleshooting. Human Performance, $1(2), 111-131$. 
Gott, S. P. (1988). Apprenticeship instruction for real-world tasks: The coordination of procedures, mental models, and strategies. Review of Research in Education, 15, 97-169.

Gramopadhye, A., Drury, C., \& Prabhu, P. (1997). Training strategies for visual inspection. Human Factors and Ergonomics in Manufacturing, 7(3), 171-196.

Hamada, K., Fujimoto, Y., \& Shintaku, E. (2002). Ship inspection support system using a product model. Journal of Marine Science and Technology, 6(4), 205-215.

Hinds, P. J., Patterson, M., \& Pfeffer, J. (2001). Bothered by abstraction: The effect of expertise on knowledge transfer and subsequent novice performance. The Journal of Applied Psychology, 86(6), 1232-1243.

Hoffman, R. R., \& Lintern, G. Eliciting and representing the knowledge of experts. (2006). In K. A. Ericsson, N. Charness, P. J. Feltovich, R. R. Hoffman (Eds.), The Cambridge handbook of expertise and expert performance (203-222). Cambridge University Press.

Hogarth, R. (1981). Beyond discrete biases: Functional and dysfunctional aspects of judgmental heuristics. Psychological Bulletin, 90, 197-217.

Hollnagel, E. (2001). Extended cognition and the future of ergonomics. Theoretical Issues in Ergonomics Science, 2(3), 309-315.

Hutchins, E. 1995. Cognition in the Wild. Cambridge, MA: MIT Press

Klein, G., \& Militello, L. (2004). The Knowledge Audit as a method for cognitive task analysis. In H. Montgomery, R. Lipshitz, \& B. Brehmer (Eds.), How professionals make decisions (335-342). Mahwah, NJ: Lawrence Erlbaum \& Associates.

Klein, G., Ross, K., Moon, B., Klein, D., Hoffman, R., \& Hollnagel, E. (2003). Macrocognition. IEEE Intelligent Systems, 18(3), 81-85.

Kraus, D. C. (1998). On-line aviation safety inspection system (OASIS): An electronic job-aid for the aircraft safety inspector. , 42(16), 1145 .

Laitinen, H., Marjamäki, M., \& Päivärinta, K. (1999). The validity of the TR safety observation method on building construction. Accident Analysis \& Prevention, 31(5), 463-472.

Latorella, K. A., \& Prabhu, P. V. (2000). A review of human error in aviation maintenance and inspection. International Journal of Industrial Ergonomics, 26(2), 133-161.

Lave, J. 1988. Cognition in Practice. Cambridge University Press, Cambridge, U.K.

Lesgold, A. (1988). Toward a theory of curriculum for use in designing intelligent instructional systems. Learning Issues for Intelligent Tutoring Systems. New York, NY: Springer-Verlag New York, Inc.

McCormick, R. (1997). Conceptual and procedural knowledge. International journal of technology and design education, 7(1/2), 141-159.

Means, B. and Gott, S. (1988). Cognitive task analysis as a basis for tutor development: Articulating abstract knowledge representations. In Psotka, J., Massey, L.D. \& Mutter, S.A. 
(Ed.), Intelligent tutoring systems: Lessons Learned (35-58). Hillsdale, NJ: Lawrence Erlbaum.

Melloy, B. J., Harris, J. M., \& Gramopadhye, A. K. (2000). Predicting the accuracy of visual search performance in the structural inspection of aircraft. International Journal of Industrial Ergonomics, 26(2), 277-283.

Meyer, B. \& Sugiyama, K. (2007). The concept of knowledge in KM: a dimensional model. Journal of Knowledge Management, 11(1), 17-36.

Militello, L. G., \& Hutton, R. J. B. (1998). Applied cognitive task analysis (ACTA): A practitioner's toolkit for understanding cognitive task demands. Ergonomics, 41(11), 16181641.

NAARSO. (2009). NAARSO Certification Program Rules. Retrieved March 16, 2009 from http://www.naarso.com/NAARSO\%20CERTIFICATION\%20PROGRAM\%20RULES\%20 $\underline{\text { Rev\%201-25-2009.pdf }}$

Patel, S., Drury, C. G., \& Lofgren, J. (1994). Design of workcards for aircraft inspection. Applied Ergonomics, 25(5), 283-293.

Patton, M.Q. 2002. Qualitative Research and Evaluation Methods. Sage Publications, Thousand Oaks, CA.

Phelps, R.H., 1977. Expert livestock judgment: A descriptive analysis of the development of expertise. In: Doctoral dissertation, Kansas State University

. Pokorny, R. A., Hall, E. P., Gallaway, M. A., \& Dibble, E. (1996). Analyzing components of work samples to evaluate performance. Military Psychology : The Official Journal of the Division of Military Psychology, American Psychological Association, 8(3), 161-177.

Schaafstal, A. (1993). Knowledge and strategies in diagnostic skill. Ergonomics, 36(11), 13051316.

Schaafstal, A., Schraagen, J. M., \& van Berlo, M. (2000). Cognitive task analysis and innovation of training: The case of structured troubleshooting. Human Factors, 42(1), 75-86.

Schneider W, Shiffrin RM. 1977. Controlled and automatic human information processing: I. Detection, search, and attention. Psychological Review, 84, 1-66.

Schraw, G. (1998). Promoting general metacognitive awareness. Instructional science, 26(1/2), 113-125.

Schreiber, G., Akkermans, H., Anjewierden, A., de Hoog, R., Shadbolt, N., Van de Velde, W., et al. (2000). Knowledge engineering and management: The CommonKADS methodology. MIT Press.

Shanteau, J. (1992). The psychology of experts: An alternative view. Expertise and Decision Support, 11, 24.

Shanteau, J. (1988). Psychological characteristics and strategies of expert decision makers. Acta Psychologica, 68, 203-15. 
Subhash, M. (2008). An inspection maintenance strategy using the inspection factor. International Journal of Quality \& Reliability Management, 25(5), 532-540.

Taylor, W., Melloy, B., Dharwada, P., Gramopadhye, A., \& Toler, J. (2004). The effects of static multiple sources of noise on the visual search component of human inspection. International Journal of Industrial Ergonomics. 34(3). 195-297.

TSSA. (n.d). Amusement Devices. Retrieved March 16, 2009, from http://www.tssa.org/regulated/amusement/default.asp

TSSA. (n.d). Elevating Devices. Retrieved March 16, 2009, from http://www.tssa.org/regulated/elevating/default.asp

Van Gog, T., Paas, F., \& Van Merrienboer, J. J. G. (2005). Uncovering expertise-related differences in troubleshooting performance: Combining eye movement and concurrent verbal protocol data. Applied Cognitive Psychology, 19(2), 205-221.

Woodcock, K. (2003). Task challenges in the performance of amusement ride inspection. Proceedings of the Human Factors and Ergonomics Society 47th Annual Meeting, 47(8), 980-984.

Woodcock, K. (2007). Modelling safety inspection: Case of amusement ride inspection. Association of Canadian Ergonomists. [CD-ROM, no pagination]

Woodcock, K. (2009). Inspecting for safety hazards. In Bust, P. (Ed.), Contemporary Ergonomics 2009 (354-362). London: Taylor \& Francis.

Xiao, Y., Milgram, P., \& Doyle, D. (1997). Capturing and modeling planning expertise in anesthesiology: Results of a field study. In C. Zsambok \& G. Klein (Ed.), Naturalistic decision making (pp. 197-205). Hillsdale, NJ: LEA.

Xiao, Y., \& Vicente, K. J. (2000). A framework for epistemological analysis in empirical (laboratory and field) studies. Human Factors, 42(1), 87-101. 